NBER WORKING PAPER SERIES

\title{
PLAYING FAVORITES: HOW FIRMS PREVENT THE REVELATION OF BAD NEWS
}

\author{
Lauren Cohen \\ Dong Lou \\ Christopher Malloy \\ Working Paper 19429 \\ http://www.nber.org/papers/w19429 \\ NATIONAL BUREAU OF ECONOMIC RESEARCH \\ 1050 Massachusetts Avenue \\ Cambridge, MA 02138 \\ September 2013
}

We would like to thank Javed Ahmed, Malcolm Baker, Lucian Bebchuk, Bo Becker, Dan Bradley, Zhi Da, Kent Daniel, Alex Edmans, Ben Esty, Andrea Frazzini, Oliver Hart, Campbell Harvey, David Hirshleifer, Louis Kaplow, Scott Kominers, S.P. Kothari, Christian Leuz, Ulrike Malmendier, Bill Mayew, Scott Mayfield, Atif Mian, Roni Michaely, Maureen O'Hara, Daniel Paravisini, Thomas Philippon, Doug Skinner, Jose Scheinkman, David Solomon, Kelly Shue, Siew-Hong Teoh, David Thesmar, Han Xia, Luigi Zingales, Eric Zitzewitz, and seminar participants at University of California Berkeley, University of California Irvine, Case Western Reserve University, University of Chicago, China Europe International Business School, Cornell University, George Washington University, University of Georgia, Georgia State University, Harvard Business School, Harvard Law School, HEC Paris, University of Hong Kong, Hong Kong University of Science and Technology, University of Illinois, Indiana University, INSEAD, London Business School, London School of Economics, University of Miami, MIT Sloan, University of Notre Dame, University of North Carolina, NYU Stern, Pontifica Universidad Catholica De Chile, Princeton University, University of Washington, UPenn Wharton, University of York, 2014 AFA Philadelphia Meeting, 2013 NBER Behavioral Economics Meeting, 2013 University of Miami Behavioral Finance Conference, 2013 Helsinki Finance Summit, 2013 Yale Doctoral Summer Program in Behavioral Finance, 2013 European Finance Association Annual Meeting, 2013 Borsa Istanbul Finance \& Economics Conference, Acadian Asset Management, AQR Capital, PanAgora Asset Management, and SAC Capital for helpful comments and discussions. We thank Alok Kumar and Kelvin Law for generously providing data on analyst brokerage house affiliation. In addition, we are grateful to James Boggie, Huaizhi Chen, Manuel Daj, David DiCenso, Barbara Esty, Laura Glass, Beth Hall, David Kim, Christine Rivera, Elizabeth Sampson, Pablo Torroella, Shannette Washington, and James Zeitler for providing excellent research assistance. We are grateful for funding from the National Science Foundation and the Paul Woolley Center at the London School of Economics. The views expressed herein are those of the authors and do not necessarily reflect the views of the National Bureau of Economic Research.

NBER working papers are circulated for discussion and comment purposes. They have not been peer-reviewed or been subject to the review by the NBER Board of Directors that accompanies official NBER publications.

(C) 2013 by Lauren Cohen, Dong Lou, and Christopher Malloy. All rights reserved. Short sections of text, not to exceed two paragraphs, may be quoted without explicit permission provided that full credit, including $(\mathcal{C}$ notice, is given to the source. 
Playing Favorites: How Firms Prevent the Revelation of Bad News

Lauren Cohen, Dong Lou, and Christopher Malloy

NBER Working Paper No. 19429

September 2013, Revised October 2016

JEL No. G0,G12,G14

\begin{abstract}
Lauren Cohen

Harvard Business School

Baker Library 273

Soldiers Field

Boston, MA 02163

and NBER

lcohen@hbs.edu

Dong Lou

Department of Finance

London School of Economics

Houghton Street

London, WC2A 2AE

UK

d.lou@1se.ac.uk

Christopher Malloy

Harvard Business School

Baker Library 277

Soldiers Field

Boston, MA 02163

and NBER

cmalloy@hbs.edu
\end{abstract}

We explore a subtle but important mechanism through which firms can control information flow to the markets. We find that firms that "cast" their conference calls by disproportionately calling on bullish analysts tend to underperform in the future. Firms that call on more favorable analysts experience more negative future earnings surprises and more future earnings restatements. A long-short portfolio that exploits this differential firm behavior earns abnormal returns of up to 149 basis points per month, or almost 18 percent per year. We find similar evidence in an international sample of earnings call transcripts from the UK, Canada, France, and Japan. Firms with higher discretionary accruals, firms that barely meet/exceed earnings expectations, and firms (and their executives) that are about to issue equity, sell shares, and exercise options, are all significantly more likely to cast their earnings calls. 
Regardless of the extent of disclosure regulations, there exists private information which managers can release at their discretion. Given the current regulatory environment in the US of level playing-field information laws, firms can only communicate information in public information exchanges. However, even in these highly regulated venues, there are subtle choices that firms can make that reveal differential amounts of information to the market.

In this paper we explore a subtle, but economically important way in which firms shape their information environments, namely through their specific organization and choreographing of earnings conference calls. Our analysis rests on a simple premise: firms have an information advantage, and they understand this and have the ability to be strategic in its release.

Our empirical strategy is to examine firms' decisions to "cast" their earnings conference calls in a particular way, specifically, how and who they call on to participate in these calls. We focus on the firms that call specifically on analysts that have given them the highest recommendations (as proxied by the average recommendation over the past year,${ }^{1}$ under the hypothesis that firms that cast their conference calls in this way may be preventing the revelation of negative information to the market. We then analyze the future behavior and outcomes associated with these firms.

To better understand our approach, consider the case of Sealed Air Corp., a firm found in our sample. Sealed Air produces a variety of packaging materials, the most wellknown of which is Bubble Wrap. Sealed Air held their Q1 earnings conference call in April 2007. While Sealed Air was covered by 11 analysts, on this particular call, it only allowed a select few to participate in the conference call: those analysts that had particularly high recommendations on the firm in advance of the call. These analysts largely complimented the firm on the quarter, but did not push them on the upcoming quarter. Figure 1 shows excerpts from the conference call: Panels A-C show several cases in which the analysts can be seen joking and laughing with the $\mathrm{CEO}$, with one analyst specifically complimenting the

\footnotetext{
${ }^{1}$ See Mayew (2008) and Mayew, Sharp, and Venkatachalam (2011) for evidence on the implications of differential analyst participation during conference calls for analyst accuracy.
} 
CEO on cash strategy. Throughout all of the exchanges there is a notable lack of difficult (or even substantive) questions posed by the analysts.

Three months later, at the Q2 earnings call following the April call where analysts with particularly positive recommendations were called upon, Sealed Air missed expectations, had their first negative free cash flow quarter (following 20 consecutive positive ones), and dropped $7 \%$ on the announcement. In this paper we show that this pattern--of firms appearing to choreograph information exchanges directly prior to the revelation of negative news--is systematic across the universe of publicly traded firms. ${ }^{2}$

More generally, our key finding is that firms that manipulate their conference calls in this way appear to be hiding bad news, which ultimately leaks out in the future. Specifically, we find that casting firms experience consistently predictable negative future returns. These negative future returns are concentrated around future earnings calls where they stop their casting behavior, and hence allow negative information to ultimately be revealed to the market. A long-short portfolio that goes long the non-casting firms and short the casting firms around their subsequent call earns abnormal returns ranging from 129 basis points $(t=2.59)$ to 149 basis points $(t=2.64)$ per month; which translates to annualized abnormal returns of roughly 15 to 18 percent per year.

Using a hand-collected dataset of international earnings transcripts, we then show that the core evidence in this paper extends beyond the U.S., to an international sample including the United Kingdom, Canada, France, and Japan. Specifically, we again find that an analyst's prior recommendation level is a strong predictor of the likelihood of asking a question on an earnings call in each of these 4 additional countries. We then show that casting on an international earnings call predicts negative future announcement returns on the subsequent earnings event, consistent with our U.S. evidence. Collectively, our evidence spans 5 countries, 13 years, 4101 firms, and 7125 analysts, covering 91,878 conference calls in total, making our dataset the largest and most extensive of any project analyzing

\footnotetext{
${ }^{2}$ Another example that occurred in April 2013 was that of the earnings call of Amazon.com, when bearish analyst Colin Gillis was locked-out of the quarterly earnings call, and leaked this to The Seattle Times. "Amazon analyst frozen out on company Q\&A calls: Analyst skeptical about Amazon wonders why he's not getting a chance to ask questions during the e-commerce giant's quarterly conference calls," The Seattle Times, May 1, 2013. At their subsequent earnings announcement (July 2013), Amazon missed analysts' expectations on EPS, missed analysts' expectations on revenues, and guided downward for future earnings.
} 
corporate earnings calls.

In terms of the magnitude and incidence of casting across the population of firms, we find that more "extreme" examples of casting -where the average gap in recommendation levels between the analysts who are called upon in a call and those who do not speak is largest (which we term RecIn-RecOut) - are associated with the most negative future returns, suggesting that the tails of this gap distribution do capture true casting behavior by firms. A one-standard deviation move above the zero recommendationgap benchmark implies that between $17-22 \%$ of firms in a given quarter engage in this type of opportunistic behavior. In the time-series we find that RecIn-RecOut is (on average) significantly higher in 2008 than in other years, consistent with the idea that casting behavior was more prevalent during the financial crisis.

Importantly, we show that the return predictability that we document is not driven by well-known predictors of future returns such as analyst forecast dispersion, analyst recommendation dispersion, discretionary accruals, affiliation status, or issuance behavior. Further, we observe no sign of any return reversal in the future, suggesting that the negative information that is hidden is information important for fundamental firm value.

If firms are deliberately choosing to call on more favorable analysts, we might expect them to do so when it is especially valuable. For instance, firms that engage in more earnings management (discretionary accruals), may be especially wary of calling on analysts that will probe into these accruals. Additionally, firms that barely meet or exceed earnings expectations (meeting at 0 , or beating by 1 penny), have been shown in prior literature to be far more likely to have manipulated earnings in order to do so, and so may be less likely to want to be aggressively questioned. Lastly, firms planning to do SEOs (or managers planning to sell their shares, or exercise their options) in the near future may be interested in keeping share price high to maximize proceeds, and so may prefer to call on friendly analysts. We find evidence on all three of these paths: firms with higher discretionary accruals, firms that barely meet/exceed earnings expectations, and firms (and their executives) about to issue equity, sell shares, and exercise stock options are all significantly more likely to call on analysts with more optimistic views of the firm.

By contrast, our evidence is less consistent with a view that the patterns we 
document are driven solely from the analyst side, i.e., that optimistic analysts are the only analysts who choose to speak on an earnings call, and that firms are merely passive actors in this process. First, the evidence on the timing of the behaviors above is hard to reconcile with this alternate view, since the analysts would have to choose to show up and speak only on the calls that exactly coincide with the firm- and manager-level opportunistic behaviors listed above, which seems implausible.

In order to further explore this alternative story, however, we also parsed our entire dataset and manually examined each conference call transcript in order to identify all the calls where phrases such as "There are no more questions in the queue" are spoken by management or by a moderator at the very end of the call. For these calls, it appears that management was not casting the call, since for these calls management actively opened up the call to the entire audience, and determined that there were no other call participants willing to ask a question. There may have been (negative) analysts who did not want to ask questions, but we can at least rule out the possibility that management was actively disallowing additional questions that the audience wished to ask. We show that these calls are not accompanied by significantly negative returns in the future (the combined effect of the "No More Questions" interaction term plus the basic "RecIn-RecOut" coefficient is insignificant for these calls); meanwhile the negative future returns described earlier are concentrated only on the calls where this phrase does not occur, suggesting that only the casted calls drive our key results.

To further explore the mechanism behind our findings, we also investigate the order of the questions asked on the earnings calls. In particular, we examine the impact of an analyst's recommendation level, All-Star status, affiliation status, and broker prestige status (along with interactions of the recommendation level with these status variables) on the order in which analysts are called on. We find that bullish analysts, All-Star analysts, affiliated analysts, and analysts from prestigious brokerage firms are called on earlier in a call. Further, the interaction terms between the recommendation level and the status variables are all significant, suggesting that bullish analysts with status are particularly likely to be called on earlier in a call.

Lastly, we attempt to get a measure of the aggressiveness of the questions asked by

Playing Favorites - Page 6 
favorable vs. non-favorable analysts. While this is a difficult task, we use a simple measure of how positive the tone of the question is (the number of positive vs. negative words). We find suggestive evidence that favorable analysts - i.e., those with higher outstanding recommendations - tend to ask more positive questions.

The remainder of the paper is organized as follows. Section I provides a brief background and literature review. Section II describes the data we use, while Section III explores firm behavior in casting earnings conference calls. Section IV examines the impact of casting on firms; Section V presents international evidence; and Section VI explores the mechanism in more detail. Section VII concludes.

\section{Background and Literature Review}

Our paper adds to a large literature examining firms' attempts to manage their information environments, the manner in which firms disclose information to the markets, and the impact of different forms of disclosure on various stakeholder groups (e.g., investors, customers, regulators, media, etc.). A series of recent papers, for example, studies the impact of Regulation Fair Disclosure ("RegFD"), which was designed to combat selective disclosure by firms. Effective October 23, 2000, companies must reveal any material information to all investors and analysts simultaneously in the case of intentional disclosures, or within 24 hours in the case of unintentional disclosures. According to SEC Proposed Rule S7-31-99, regulators believed that allowing selective disclosure was "not in the best interests of investors or the securities markets generally." Several recent papers examining the impact of Regulation FD on the behavior of equity analysts conclude that the law has in fact been effective in curtailing selective disclosure to analysts (see, for example, Mohanram and Sunder (2006), Groysberg, Healy, Chapman, Shanthikumar and Gui (2007), Cohen, Frazzini, and Malloy (2010), Agrawal, Chadha, and Chen (2006), and Gintschel and Markov (2004)). Our paper is unique in that we take as given the "level playing field" imposed by Regulation Fair Disclosure (RegFD), and explore the subtle

choices firms can make even within this seemingly strict information disclosure environment, choices that can (as we document) have large implications for market prices and firm outcomes.

Playing Favorites - Page 7 
Since the laboratory we exploit is that of quarterly earnings conference calls, our paper is also relevant to a large literature studying the relationship between firms and analysts, as well as studies of the information content of earnings announcements and earnings conference calls specifically. ${ }^{3}$ For example, a recent strand of the literature examines management communication during conference calls and its association with information content (Hollander, Pronk and Roelofsen (2010), Matsumoto, Pronk and Roelofsen (2011)), information asymmetry (Chen, Hollander, and Law (2014)), future performance (Mayew and Venkatachalam (2012)) and financial fraud and misreporting (Larcker and Zakolyukina (2011), and Hobson, Mayew and Venkatachalam (2012)). In addition, Zhou (2014) uses textual analysis to analyze when corporate executives blame poor performance on external factors such as the industry or the broader economy. Chen and Matsumoto (2006) also find that in the pre-Reg FD period that analysts with access to management deliver more accurate earnings forecasts. Lastly, Mayew (2008) and Mayew, Sharp, and Venkatachalam (2013) also document and explore differential analyst participation on conference calls, but focus on its implications for analyst accuracy; our focus is on the firms engaging in this type of behavior, and the signal that this behavior conveys for future firm outcomes.

\section{Data and Summary Statistics}

We draw from a variety of data sources to construct the sample we use in this paper. A critical input to our study is the earnings conference call transcript data. We obtain these transcripts from Thomson Reuters, specifically from the StreetEvents data feed. We collect the complete transcripts of all US conference calls for the period of 2003 to 2015. We also obtain, from the same source, all available conference calls in Canada, UK, France, and Japan for the period of 2003 to 2014. We isolate the name of the firm conducting the call, along with the name and affiliation of all analysts covering the firm conducting the call. In practice, firms know the identities of all listeners to the call, as

\footnotetext{
${ }^{3}$ For instance, Hirshleifer et al. (2009), DellaVigna and Pollet (2009), and Neissner (2013) all give evidence that managers attempt to time disclosures around times of low perceived investor attention. There is also an accompanying literature examining the release of negative news (see, for example Kothari et al. (2009), Bergman and Roychowdhury (2008), and Westphal and Deephouse (2011)).
} 
each person must dial in through a conference call-in service that requires them to sign in at the outset of each call; the company then filters who can ask questions, and also determines the queue. ${ }^{4}$ In the Thomson data, we see only the names of analysts who were called on to ask a question during the call; we assume that all other analysts covering the stock were listening to the call, but were not called on. ${ }^{5}$

To construct our dataset, we first hand-match the StreetEvents analyst names for each call back to the brokerage house and analyst last name and first initial available on IBES, using a conservative matching procedure. This allows us to match the data to IBES, so that we can obtain data on past forecast accuracy and past recommendation levels. For some of our additional tests, we also examine the text of each question in order to assess the difficulty of the question.

In addition to analysts' past forecasts and recommendations, we also obtain analyst data on length of career, Institutional Investor All Star status, and other selected analyst biographical items (such as past employment) from ZoomInfo. We also collect additional firm-level data, such as firm restatements over our sample period from the Audit Analytics database, as well as monthly stock returns, shares outstanding, volume, and market capitalization from CRSP, and a variety of firm-specific accounting variables from Compustat. For our international sample, we obtain their daily stock returns from

\footnotetext{
${ }^{4}$ With regard to the call mechanics, we have contacted, and had a number of discussions with, the company InterCall (a subsidiary of West Corporation), which administers over $85 \%$ of all quarterly conference calls for the Fortune 100. Many employ the industry-standard product called Leader-View, which allows a firm's "call-team" - which from InterCall has a modal constituency of the CEO/CFO, head of Investor Relations, Legal Counsel, and two to three other company executives - to see a computer screen with everyone that has entered the call. This "call-team" then has a private line to the operator at InterCall who is orchestrating the call. What the firm sees on Leader-View is a list of participants in the call, along with affiliation of each participant, and a flag for whether the participant has indicated interest in asking a question during the Q\&A. Through their private communication line, the firm's call-team indicates to the operator who it would like to call on, and at what point during the call it would like to call on that participant. The operator then introduces the questioner chosen by the firm - this is why conference call transcripts are filled with lines such as: "Operator: Next up we'll hear from Colin Gillis from BGC Partners." At the firm's discretion, the Q\&A portion of the call comes to a close. We attempted to obtain the full participant list from both InterCall and the underlying firms, but neither would provide the full set of participants (nor the set of participants that "indicated" they wanted to ask a question, but were not able to).

${ }^{5}$ In Appendix Table A7 we show that analysts who are able to ask questions during the call have significant increases in their future forecast accuracy following the call. Anecdotally, we also contacted a number of analysts directly, and in those conversations the analysts commented that it was a "job-requirement" to callin (and if possible to ask questions) during the conference calls. One recounted an instance where a leadanalyst at his firm had not called in, and it being mentioned at the lead analyst's performance review.
} 
Datastream. In sum, our evidence spans 5 countries, 13 years, 4101 firms, and 7125 analysts, covering 91,878 conference calls.

Table I presents summary statistics from our final dataset. Panel A reports statistics for our U.S. dataset, and Panel B reports numbers for our pooled international dataset, consisting of observations from the UK, Canada, France, and Japan. Each analyst covering a given stock is designated as "in" for a particular conference call if she was called on during that call, and "out" if she was not called on during that call. An analyst is said to be "covering" a stock if she has produced a stock recommendation for a given stock in the IBES database in the past year. Table I shows that an average of 3.73 unique analysts (out of an average of 9.93 analysts covering a stock) are called on during a typical quarterly earnings call. In a preview of some of our results, Table I also shows that analysts who are called tend to issue more optimistic recommendations in the year prior to the call (an average of 3.75 on a $1-5$ scale, where $1=$ Strong Sell, $2=$ Sell, $3=$ Hold, $4=$ Buy, $5=$ Strong Buy) relative to other analysts covering the stock $(=3.61)$. The average level difference in analyst recommendations between the two groups (equal to 0.15) is statistically significant and of the same magnitude as the optimism effect associated with "affiliation" (i.e., when a firm has an underwriting relationship with the analyst's brokerage house), which is the subject of a vast analyst literature (see, for example, Lin and McNichols (1998), Lin et al. (2005), Michaely and Womack (1999), Hong and Kubik (2003)). Panel B shows a similar, although somewhat smaller, unconditional difference between the average recommendation levels of the two analyst groups (RecIn-RecOut=0.08) in the international data. Note that Appendix Table A1 reports some additional firm-level summary statistics; relative to the average firm on CRSP, our sample is tilted towards stocks that are larger, have lower bookto-market ratios (i.e., are more "growth-like" in nature), and have higher institutional ownership.

\section{Firm Behavior on Earnings Conference Calls}

\section{A. Analyst Recommendations and Conference Call Participation}

We begin by examining the likelihood of an analyst being called upon in a quarterly earnings conference call. Specifically, we run panel regressions where the dependent 
variable $(I N)$ is an indicator variable equal to 1 if the analyst was called on during a call, and 0 if the analyst was not; the main independent variable of interest is the analyst's recommendation level prior to the conference call. We focus on the average recommendation in the year prior to the call rather than the most recent recommendation of each analyst; this is because firm managers may not be immediately aware of the most recent recommendation updates by individual analysts, and thus have to rely on the historical average to identify "friendly" vs. "unfriendly" analysts. Using lagged recommendations also helps alleviate the concern that our results are driven by the information content of recent recommendation changes.

We also control for a variety of other determinants of call participation, including several analyst-level variables (such as the number of years the analyst has worked in the industry, the number of years the analyst has covered the firm in question, the number of stocks currently covered by the analyst, the number of stocks currently covered by the analyst's brokerage firm, a dummy if the analyst was named an Institutional Investor AllStar analyst within the past year, and a dummy indicating whether the analyst is affiliated with a brokerage house that underwrites for the firm in question ${ }^{6}$ ), and numerous firmlevel measures (such as size, book-to-market ratio, past year returns, share turnover, and idiosyncratic volatility). We then test the hypothesis that firms choose to call on or "cast" their earnings calls with analysts who were more favorable in their past recommendations on these firms.

Table II, using data on all US publicly traded firms from 2003-2015, confirms the finding in Mayew (2008) that firms do indeed call on analysts who issue more favorable recommendations in the year leading up to a conference call. Further, Table II shows that this effect persists even after controlling for a host of analyst- and firm-level variables known to correlate with analyst recommendations, and after including firm-quarter fixed effects (in Columns 1-2, thus comparing in and out analysts covering the same firm in the same quarter), and after including analyst-time fixed effects (in Columns 3-4, thus comparing in and out stocks covered by the same analyst in the same quarter). ${ }^{7}$ The

\footnotetext{
${ }^{6}$ We thank Alok Kumar and Kelvin Law for providing data on affiliation of all analysts and brokerage houses in our sample. See Kumar (2010) for more details.

${ }^{7}$ Appendix Table A2 shows that controlling directly for the number of times the analyst has been called on Playing Favorites - Page 11
} 
estimates in Columns 1-4 imply that for a one-notch increase in analyst recommendation level (roughly a one-standard deviation move), the likelihood of being called on increases by about $6 \%$, relative to an unconditional probability of $38 \%$ (so a $16 \%$ increase in the likelihood). In Columns 5 and 6 , we run the same regressions but now using a logit specification, again using being "called on" as the 0/1 dependent variable, and the average prior recommendation level (minus the average recommendation level for that firm prior to the call) as the independent variable of interest; these tests again reveal a positive and significant effect of prior recommendation level on the likelihood of being called on during an earnings conference call. In terms of economic magnitude, the marginal effect of a onestandard-deviation increase in recommendation is associated with a 5.7\%-6.9\% increase in the likelihood of being called.

\section{B. Types of Firms that Call on Bullish Analysts, and Incidence of Casting}

Next we examine the behavior and characteristics of firms that tend to call specifically on analysts with higher past recommendations. Our first test explores the determinants of firms' casting decisions. Our key measure of casting, RecIn-RecOut, equals the difference in average recommendation level by "in" analysts (i.e., those analysts called upon during the conference call) versus "out" analysts (i.e., those analysts not called upon, but who cover the firm in the given quarter), measured in the one year prior to the conference call. We then run panel regressions with this firm-level (RecIn-RecOut) variable on the left-hand side of the regression, and present the results in Table III. ${ }^{8}$

For our explanatory variables, we start by analyzing two measures that plausibly capture a firm's incentive to call on more favorable analysts. First, we examine discretionary accruals, as firms with higher accruals may have an incentive to call on bullish analysts to avoid a potentially unfavorable discussion of the specific composition of their earnings. We also create a dummy variable equal to one if a firm's earnings surprise in the

in the past (PASTCALL), has no effect on these results from Table II. Also note that including firm-analyst fixed effects in these Table II regressions has no effect on the results either.

${ }^{8}$ We find nearly identical results using an alternate measure of casting, termed RecIn $>$ RecOut, which is a dummy variable equal to 1 if the average recommendation of analysts speaking on the call is higher than the average recommendation of those who do not speak on the call. 
quarter in question is exactly 0 or 1 cent, since firms that just meet (or barely exceed) consensus forecasts may want to avoid any difficult questions about the precise manner in which they hit their forecasts so narrowly.

We also control for the same firm-level variables defined in Table II, and run the tests as panel regressions with firm and time (quarter) fixed effects and standard errors double-clustered at both the firm and quarter level. In addition, we include controls for: analyst forecast dispersion (measured as the standard deviation of analysts' outstanding quarterly EPS forecasts); and analyst recommendation dispersion (measured as the standard deviation of analysts' outstanding recommendations); analyst coverage (the number of unique analyst estimates made in the 12 months leading up to the call); institutional ownership (the proportion of the firm that is held by institutional investors); and the idiosyncratic volatility of the firm (measured as the standard deviation of the fourfactor adjusted monthly return over the past 12 months).

Columns 1-3 of Table III show that discretionary accruals (ACCRUAL) and the dummy for meeting or barely exceeding consensus earnings forecasts $(S U E(O))$ are both positive and significant predictors of RecIn-RecOut, consistent with the idea that firms with the largest incentive to call on favorable analysts are exactly the firms that do so. In terms of magnitude, a one-standard deviation move in accruals leads to a $6.5 \%$ increase in RecIn-RecOut. In addition, firms that meet or barely exceed forecasts have a $20 \%$ higher value of RecIn-RecOut. ${ }^{9}$

In Columns 4-7 of Table III we explore the future behavior of firms after they engage in casting behavior. Specifically, we run logit regressions in order to examine the predictive power of casting on a given call for several firm (and executive) behaviors during the following quarter. Our first dependent variable is a dummy variable equal to one if the firm in question issues a secondary equity offering (SEO) in quarter $t+1$, as firms issuing equity in the near future may want to avoid the release of any potential bad news that could decrease their issuance proceeds. Second, we create a dummy variable equal to one if the insiders of the firm conducting the call on aggregate engage in net-selling of their

${ }^{9}$ Controlling for the magnitude of the SUE (standardized unexpected earnings) itself in all of the regressions in Table III has no effect on these results.

Playing Favorites - Page 13 
insider owned shares - the idea being that firms may want to prop up their stock price (delay the release of bad news) if they plan to engage in sales of their shares, as they would like to sell the shares at the highest price possible. Third, we create a dummy variable equal to one if a firm's top executives exercise their stock options in the following quarter, and zero otherwise; again the idea is that executives ideally would like to exercise their options at the highest share-price possible. And finally, we create a dummy variable equal to one if a firm's top executives receive an option grant in the following quarter, and zero otherwise; here the idea is the opposite of the exercise variable, since in this case an executive hopes to receive a grant at the lowest price possible.

Columns 4-7 show that casting behavior (RecIn-RecOut) is indeed a positive and significant predictor of future equity issuance (SEO), future insider selling (INSIDER), and future option exercise by management (OPTIONEXCS), and a negative and significant predictor of option grants $(G R A N T)$. In terms of marginal impact, a one-standard deviation move in RecIn-RecOut leads to a $6 \%$ increase in the likelihood of SEO issuance, a $3 \%$ increase in the likelihood of insider selling, a $2 \%$ increase in the likelihood of option exercise by management, and a $5 \%$ decrease in the likelihood of option grants given to management (all as a fraction of their corresponding unconditional probabilities).

One important question is the extent to which we are capturing the information staging activities of a few firms that engage in this frequently throughout our sample, or whether this is a more systematic activity engaged in by a large universe of firms at precisely those times when it is most valuable for any given firm to withhold negative information. However, note that Columns 1-3 of Table III include both firm and quarter fixed effects. ${ }^{10}$ If it were simply a subset of firms always casting their calls, the firm fixed effect would capture this, and these independent variables would be insignificant upon the inclusion of the fixed effects. In contrast, Table III shows that even controlling for firm fixed effects, all of the results on motivators for potentially wanting to cast a call (e.g., earnings management) are highly significant.

One persistent firm-level variable worth mentioning is the corporate governance G-

10 Note that if we re-run Columns 4-7 using OLS with firm and quarter fixed effects, instead of logit regressions, the results are similar to those presented here.

Playing Favorites - Page 14 
index measure of Gompers, Ishii, and Metrick (2003). This measure is highly persistent at the firm level, so one would expect that firm fixed effects would largely capture this measure, and we confirm this in our data. Without firm fixed effects, the coefficient on the G-Index is $0.0037(t=2.37)$, suggesting that casting behavior is positively related to poor governance, but this result is no longer significant once firm fixed effects are included.

In Figure 2 we graph the histogram of frequency of quarters that each firm casting episode in our sample lasts. In theory, once a firm begins to "cast" their conference call (RecIn $>$ RecOut), they could continue this behavior indefinitely. As we have 36 quarters in our sample, if the firm is present throughout the entire sample, the maximum casting length could be 36 quarters, with the minimum 1 (as we are conditioning on it being a casting episode). What we see from Figure 2 is that the most common length for a casting episode is one quarter. Also note that in Appendix Figure A1, we compute two "placebo" figures, one of which represents a histogram of casting spells under the assumption that firms calls on firms randomly, and another which is a histogram of spells of non-casting episodes (where RecIn $<$ RecOut); the casting distribution depicted in Figure 2 is noticeably more fat-tailed relative to these two placebos, and also statistically different from both in a Chi-Squared test.

These histograms, along with the firm fixed effects not impacting the results in Table III, suggests that casting is something a wide range of firms engage in selectively at precisely those times they have strong incentives to do so, and we are not identifying a behavior solely driven by a few firms that continuously cast their calls.

To further explore the magnitude and incidence of casting across time and across the population of firms in our sample, Table IV plots the distribution of casting (RecInRecOut) by year, both according to percentiles of the distribution (in Panel A), and using fixed thresholds (in Panel B). As we show later in Table VI, exploring the tails of the casting distribution (i.e., firms where RecIn-RecOut is particularly high, e.g., greater than the $90 \%$ percentile) results in even stronger results than our baseline findings, suggesting that these higher thresholds capture "extreme" casting more cleanly. Panel A of Table IV shows that RecIn-RecOut is (on average) significantly higher in 2008 than in other years, consistent with the idea that casting behavior was more prevalent during the financial 
crisis. Panel B indicates that the percentage of firms with RecIn-RecOut $>0$ is roughly $60 \%$ across the sample. At the threshold of 0.6 (a one-standard deviation move above the RecInRecout $=0$ benchmark), we find between $17-22 \%$ of firms in a given quarter fall into this category; this number represents a possible estimate of the general incidence of casting in the population of firms.

Collectively, the results in this section indicate that during our full 2003-2015 sample of the universe of quarterly earnings calls, firms are more likely to call on analysts who have issued more favorable recommendations on these firms leading up to the call. Moreover, this type of behavior is most pronounced among firms with the strongest incentives to manage the flow of information to the market, such as firms with higher discretionary accruals, firms that barely meet/exceed earnings expectations, and firms (or executives) about to issue equity, sell shares, or exercise their stock options in the near future.

\section{The Impact of Casting on Firms}

In this section we explore what happens to the firms that call on more favorable analysts during earnings conference calls. We exploit cross-sectional and time series variation in the extent to which firms engage in this type of behavior, and importantly when they choose to cast their calls. We explore the impact of casting on a host of future firm-specific outcomes, such as future stock returns, future earnings surprises, and future earnings restatements.

\section{A. Future Earnings Announcement Returns and Future Earnings Surprises}

If firms calling on favorable analysts are doing so in order to portray the most positive view to the market and potentially hide any negative information from coming to light, our hypothesis is that firms engaging in this type of behavior are more likely to experience negative future outcomes, such as negative future earnings surprises, as this news will ultimately be revealed to the market (it likely cannot be hidden forever). We test this idea by running forecasting regressions of future earnings announcement returns 
and future earnings surprises on the lagged spread between average recommendation levels (in the prior year) of analysts called on vs. those not called on (RecIn-RecOut) during the last earnings call, plus a host of additional control variables. We measure announcement returns using cumulative abnormal returns (CARs) around the earnings date, and earnings surprises using SUEs, and control for the same firm-level variables used in Table III. Again, since these CARs and earnings surprises are measured around the subsequent earnings announcement relative to the one-quarter lagged casting measure, these regressions are strictly predictive in nature. We conduct quarterly Fama-MacBeth regressions for both CARs and SUEs, controlling for the following lagged firm-level variables: market capitalization; book-to-market ratio; prior year returns; share turnover over the past 12 months; analysts' recommendation dispersion; idiosyncratic volatility, institutional holdings, and analyst coverage.

Columns 1-3 of Table $\mathrm{V}$ show that firms that call more on favorable analysts (i.e., those with higher values of RecIn-RecOut) experience more negative future announcement returns (CARs). For example, the coefficient of -0.259 in Column 3 implies that for a onestandard deviation move in (RecIn-RecOut) this period, CARs are $39 \%$ lower at the next announcement (computed relative to the sample mean CAR of 40 basis points). Controlling for additional known predictors of future earnings returns, such as net insider selling behavior, discretionary accruals (Sloan (1996), Hirshleifer, Hou, and Teoh (2012), etc.), analyst forecast dispersion (Diether et al. (2002)), etc., have no effect on this return predictability. ${ }^{11}$ Columns 4-6 of Table V show a similar effect for future earnings surprises. In terms of the magnitude of this effect, a one-standard deviation move in (RecIn-RecOut) this period implies a lower earnings surprise by over $20 \%$ of the interquartile range for the next announcement, so an economically large impact.

\section{B. Isolating Cases Where Management Left No Questions Unanswered}

Our evidence so far is less consistent with a view that the patterns we document are

\footnotetext{
${ }^{11}$ Also if we run these regressions on the set of firms who do not issue SEOs, to ensure that our results are not driven by post-SEO underperformance, we find that the coefficient on RecIn-RecOut in predicting future CARs is $-0.229(t=2.38)$, which is very similar to the figure reported in Column 3 of Table V.
} 
driven solely from the analyst side, i.e., that optimistic analysts are the only analysts who choose to speak on an earnings call, and that firms are merely passive actors in this process. In particular, the timing of the firm-level behaviors documented in Section III.B is hard to reconcile with this alternate view, since the analysts would have to choose to show up and speak only on the calls that exactly coincide with these behaviors, which seems implausible.

That said, we cannot "prove" that management denied access to particular analysts on a given call, since we do not have data on the "operator lists" that flag all those wishing to ask questions. ${ }^{12}$ In order to further explore this alternative story, however, we also went through and parsed our entire dataset and manually examined each conference call transcript in order to identify all the calls where phrases such as "There are no more questions in the queue" are spoken by management or by a moderator at the very end of the call. For these calls, it appears that management was not casting the call, since for these calls management actively entertained and took all questions from the call participants, ostensibly ending the conference call only when there were no further questions. Therefore, for these calls we can plausibly assume that management was at least not "refusing" to allow any additional questions from certain analysts in the audience. There may have been (negative) analysts who did not want to ask questions, but we can at least rule out the possibility that management was actively disallowing additional questions that the audience wished to ask.

We take this set of calls and create a dummy variable called "NoMoreQuestion" which is set equal to one for all the calls where phrases such as ("There are no more questions in the queue") are used to close the call. We find that these types of phrases are used in 25-30\% of the calls. In Panel B of Table V, we then interact this dummy variable with our indicator for a casted call (RecIn-RecOut), and re-run the basic future earnings CAR test from Table V. The idea is that for these calls in which (presumably) all questions have been allowed to be asked, the firm is not then casting the call. Thus, any variation in (RecIn-RecOut) we observe in these calls should essentially be random noise, such that (RecIn-RecOut) will mean something different for these non-casted calls. In particular,

\footnotetext{
${ }^{12}$ As mentioned above, we attempted numerous times (and methods) of obtaining the full participant list from both InterCall and the underlying firms, but neither would provide the full set of participants (nor the set of participants that "indicated" they wanted to ask a question, but were not able to).
}

Playing Favorites - Page 18 
(RecIn-RecOut) now being random, it should have no predictive power for future firm earnings events, returns, etc., in contrast to what we see for choreographed earnings calls.

The results are shown in the new Table V, Panel B. The interaction term of (RecInRecOut) and NoMoreQuestion is significantly positive. Further, combining this with the main effect on (RecIn-RecOut) gives an estimated impact of (RecIn-RecOut) in calls where all questions are allowed to be asked that is statistically equal to zero for both future earnings surprises and returns around those future earnings events. Meanwhile, the negative returns are concentrated on the calls where this phrase does *not* occur, which in our view are much more likely to be the strategically cast calls that drive our key results.

Collectively, our results appear consistent with a view that firms are - at the very least - active partner participants in this process, in terms of being opportunistic with information release, and as such are taking an active role in casting these calls.

\section{C. "Extreme" Cases of Casting}

In Table VI we explore the ability of the extreme tails of the distribution of casting (RecIn-RecOut) to predict future CARs. We do this in order to examine if the return predictability we document in Table $\mathrm{V}$ increases monotonically as the extent of casting increases, as our thesis would suggest if casting is driving the future return relationship we have documented. Specifically, Table VI replicates the approach in Table V but employs a dummy variable construction for the variable of interest (RecIn-RecOut), and explores the impact of casting above certain thresholds. For instance, Column 6 of Table VI shows that the coefficient on casting "greater than 90\%" (meaning that the value of RecIn-RecOut for that firm is above the $90^{\text {th }}$ percentile across all firms in a given quarter) is -0.430 $(t=2.77)$, which is larger than the coefficient on casting above the $75 \%$ threshold $(=-0.327$, $t=2.17) \cdot{ }^{13}$

\footnotetext{
${ }^{13}$ We have also broken out earnings announcements associated with firms' fiscal year-ends, to examine if the results are stronger at these times, but the coefficient on RecIn-RecOut in predicting future CARs is not significantly different from the coefficient reported in Table $\mathrm{V}$ for the full sample.
} 


\section{Portfolio Returns}

Next we employ a portfolio approach to examine if the CAR returns documented above show up in calendar-time portfolios. To do so, each day we sort all stocks into quintiles based on RecIn-RecOut in the prior quarter. Then during the five days around their next earnings announcement, we long the stocks whose RecIn-RecOut in the previous quarter is in the bottom quintile (i.e., the firms exhibiting the least amount of casting), and short the stocks whose RecIn-RecOut in the previous quarter is in the highest quintile (i.e., the firms exhibiting the most amount of casting). The reason we choose the next announcement is that (as shown in Figure 2) the one quarter horizon is by far the most common length of casting by firms. To construct these portfolios, if on any given day there are less than or equal to five stocks on either the long or short side, we hold the 30-day Treasury bill instead. The portfolios are rebalanced daily, and aggregated up to monthly figures that are reported in Table VII. Panel A presents excess returns (in excess of the 3month Treasury bill), 1-factor (CAPM), 3-factor Fama-French, 4-factor Carhart, and 5factor (including the Pastor-Stambaugh liquidity factor) alphas, and Panel B presents factor loadings. ${ }^{14}$

Panel A of Table VII indicates that the Long/Short (Q1 minus Q5) portfolio earns monthly abnormal returns ranging from 129 basis points $(t=2.59)$ to 149 basis points $(t=2.64)$ per month, or roughly 18 percent abnormal returns per year. ${ }^{15}$ Out of the 129 basis points, around $38 \%$ is due to the spread on the long side (Q1 minus Q3), and the remaining $62 \%$ due to the spread on the short side (Q5 minus Q3). ${ }^{16}$

Importantly, as shown earlier in Table $\mathrm{V}$ in a regression context, Appendix Table A3 also demonstrates in a portfolio setting that the return predictability we demonstrate in this paper is not simply a repackaging of the well-known predictability associated with

\footnotetext{
${ }^{14}$ Note that here in these initial tests we are using the daily, realized timing of earnings announcements, which may not be perfectly knowable in advance. In Appendix Table A4, we instead use predicted earnings announcement months, which are forecasted a year in advance, and present the returns to simple monthly, calendar-time portfolios using these, in addition.

${ }^{15}$ This portfolio return result is not driven by Friday announcements. Excluding all Friday announcements, the spread portfolio still earns 123 basis points per month $(t=2.53)$.

${ }^{16}$ As can be seen from Panel A of Table VII, the average abnormal return across all quintiles in our sample is positive. This is consistent with a large literature (see Frazzini and Lamont (2006) for a summary) documenting an "earnings announcement premium" for all stocks announcing earnings in a particular month.
} 
either discretionary accruals or analyst forecast dispersion. Controlling for both accruals and forecast dispersion as factor mimicking portfolios, we show that the return predictability associated with casting conference calls remains large and significant.

Note that the negative information that firms appear to be hiding by casting their calls could be released into the market at any point following the earnings call. Transcriptions of the calls are publicly available during our sample period usually within hours (or minutes) of the call itself. ${ }^{17}$ Therefore, while the next earnings announcement (and conference call) provides a natural information revelation event (that is also standardized across firms in its occurrence), it is not necessarily the time at which the bad news is revealed.

In Appendix Figure A2, we thus examine event time returns following the earnings call that was cast by the firm. This figure plots the event time abnormal stock returns for the 12 months following portfolio formation of the long-short portfolio in Table VII (short firms that cast, long firms that do not cast). The figure begins charting abnormal returns (DGTW characteristically-adjusted) directly after the earnings announcement in which the firm cast (or did not cast). We see that the returns to this L-S portfolio concentrate primarily around the subsequent earnings announcement (Month 3). Critically, while there is a return shock at the subsequent earnings call, this shock in abnormal returns never reverses following Month 3. Given that prices react sharply around subsequent information revelation and never revert, far from being overreaction, this suggests that the negative information that was hidden by the firms, and is subsequently revealed, is information fundamentally important for firm value.

\section{E. Future Earnings Restatements}

Given the findings on future negative earnings surprises, and the future negative stock returns associated with these casting firms, and in particular the results in Table III suggesting that casting firms tend to be those with higher discretionary accruals, a natural question is to what extent this type of behavior predicts future earnings restatements and accounting irregularities. Ultimately, in the future the market seems to realize the negative

\footnotetext{
${ }^{17}$ For instance, Morningstar, Inc. and Thomson Reuters offer subscription products, while Seeking Alpha and Earnings Impact offer free access to transcripts following earnings calls.
} 
information that these firms were withholding during their prior earnings calls, and in the same manner we might expect abnormal accruals ultimately may be undone in the form of future earnings restatements. To test this conjecture, we run a predictive regression of future restatements (drawn from the Audit Analytics database) in quarter $t+1$ on lagged RecIn-RecOut, plus the same firm-level control variables used in Tables V and VI. Table VIII confirms that RecIn-RecOut is a positive and significant predictor of future earnings restatements. In particular, as shown in Columns 1-3, a one standard-deviation move in (RecIn-RecOut) this period predicts a $32 \%$ increase in the likelihood of future restatements by the firm, as a fraction of the unconditional probability of having a restatement. Again, as can be seen in Columns 4-6, this result is concentrated in conference calls where the management is likely to be casting, and completely disappears if we focus solely on the set of conference calls ending with no more questions in the queue.

\section{International Evidence}

In this section, we explore international evidence on earnings conference calls. We do this for two reasons. First, any paper that shows evidence of stock return predictability is strengthened by the use of out-of-sample evidence, since this helps to assuage concerns about data mining. Second, the U.S. sample period we explore in Section IV all takes place in the period after the enactment of Regulation Fair Disclosure (RegFD) (in August of 2000) as well as the subsequent Global Analyst Research Settlement (in April of 2003). RegFD mandated that all publicly traded companies must disclose material information to all investors at the same time, and potentially changed the extent to which analysts can benefit from especially close relationships with firms (e.g., through additional underwriting links between their brokerage house and the firms in question). The Global Settlement was an enforcement agreement reached between the SEC, NASD, NYSE, and ten of the largest brokerage houses that sought to address conflicts of interest within brokerage houses specifically with regard to analyst recommendations.

Although these changes mean that our sample takes place entirely within the current regulatory regime--and hence the most relevant one on a forward-looking basis - in this section we explore out-of-sample evidence to investigate whether or not our findings extend 
to other settings and other regulatory regimes. We cannot go back to the "pre-RegFD" sample, because we do not have transcript data available in that period, ${ }^{18}$ but we can explore international evidence. As described in Cohen, Frazzini, and Malloy (2010), the regulatory environment in many other countries (e.g., the United Kingdom) did not change over this period, meaning that the structural shift in the disclosure environment experienced in the U.S. since the early 2000s has not been replicated outside the U.S. Therefore, exploring non-U.S. evidence can help determine the extent to which our findings are confined to the current U.S. regulatory environment.

To investigate this question, we compile international transcript data from four countries: the United Kingdom, France, Canada, and Japan. This required an intensive hand-matching process in order to match these transcripts to the firms and analysts listed in the $\mathrm{I} / \mathrm{B} / \mathrm{E} / \mathrm{S}$ database. Collectively, the international sample contains an additional 7770 unique conference calls, covering 637 firms, 2723 analysts, and 12 years.

In Table IX we replicate our tests from Table II that explore the likelihood of being called on during a conference call, for these four foreign countries. As in Table II, the dependent variable in Table IX is an indicator that takes the value of one if the analyst asks a question on the call, and zero otherwise. Columns 1, 3, 5, and 7 of Table IX conduct a panel OLS regression, where the main independent variable is the average recommendation level of the analyst in the year prior to the conference call $(R E C D)$; Columns 2, 4, 6, and 8 conduct a pooled logit regression, where the main independent variable is the average prior-year recommendation level of the analyst relative to the firm's consensus recommendation $\left(R E C D^{a d j}\right)$. Columns $1,3,5$, and 7 also include firm*quarter fixed effects.

Table IX shows that for all specifications, across all four countries, the level of an analyst's prior recommendation is a positive and significant predictor of the likelihood of being called on during an earnings call. In terms of the marginal effect (from the logit regressions), a one-standard deviation move in recommendation level is associated with a $2.2 \%, 1.8 \%, 1.2 \%$, and $2.2 \%$ increase in the likelihood of having the opportunity to ask a

\footnotetext{
${ }^{18}$ We attempted to obtain data pre-2003, but Thomson only kept electronic transcripts of conference calls
} starting in 2003, and we could not find another source that had transcribed data before this time period.

Playing Favorites - Page 23 
question in a conference call in Canada, UK, France, and Japan, respectively. Collectively, these findings confirm that casting behavior by corporations on earnings conference calls is an international phenomenon, and not one that is confined to the U.S., or to the current regulatory regime in the U.S.

Next we examine the future earnings announcement returns associated with the casting behavior that we observe outside the U.S. We present these results in Table X. As in Table $\mathrm{V}$, this table reports forecasting regressions of earnings announcement day returns on lagged differences in average recommendations between analysts that ask questions in the conference call and those that do not in the international setting. Our sample includes conference calls in four foreign countries: Canada (column 1), UK (column 2), France (column 3), and Japan (column 4). In column 5, we pool all observations from the four countries together. The dependent variable in each column is the cumulative abnormal return in the five day window around the future subsequent earnings announcement (CAR, in \%). The main independent variable is a dummy variable equal to one if the average lagged recommendation level of in-analysts is larger than that of outanalysts (RecIn-RecOut), and zero otherwise.

Consistent with the U.S. evidence, Table $\mathrm{X}$ shows that casting behavior on an international earnings call predicts significantly negative future announcement returns on the subsequent earnings event. This finding holds true for all four foreign countries. In terms of magnitude, as shown in Column 5, when pooling observations across all four countries, we find that a one-standard-deviation move in RecIn-RecOut predicts a 32bp $(t=3.21)$ lower earnings announcement return in the next quarter.

In sum, the out-of-sample evidence we present in this section suggests that our U.S. evidence is unlikely to be a result of data mining, nor is it confined to a particular regulatory regime in the U.S. Rather, the casting phenomenon we document, and the impact of this behavior on future stock returns, is a global phenomenon engaged in - and experienced by - worldwide financial markets.

\section{Additional Tests of Mechanism and Discussion}

In this final section we explore the mechanism at work behind our results in greater 
depth. To do so, we investigate the nature of the questions asked during earnings calls in more detail, both by examining the ordering of analysts called upon during the conference call, and by conducting exploratory textual analysis. We conclude by discussing some potential costs and benefits of the casting phenomenon we document, for both firms and analysts.

\section{A. Order of Analysts Called Upon During Call}

First, we examine the order that analysts are called on during these earnings calls. The results in Table II (regarding more favorable analysts being called upon during the call), imply a natural extension of our tests to examine not just who participates, but when they participate on a call. If company behavior is pre-meditated (and the length of the call is somewhat unknown), one would suspect that the true favorites (i.e., bullish analysts) might be called upon earlier in the call. This favoritism in ordering might also extend to other analysts with observably "high status" (e.g., All-Star analysts, and/or analysts from an affiliated or prestigious brokerage house), followed by analysts from the largest brokerage firms, followed by the small firm analysts, and so on down the line.

Table XI examines the order in which analysts are called upon conditional on being in the conference call. Thus, this analysis is independent of that in Table II, in that it examines solely within-call ordering conditional on call participation (as opposed to participation or not). The dependent variable in all columns represents the order of the analysts asking questions (e.g., the first questioner would have a value of one). The main independent variables include: the recommendation level of the analyst prior to the conference call $(R E C D)$, whether the analyst is an all-star analyst (ALLSTAR), whether the analyst is affiliated with a broker that underwrites for the firm in question (AFFILIATE), and the number of All-Star analysts employed by the broker (PRESTIGE), which is a common measure of broker prestige. We also interact the analyst's recommendation with these "high status" variables.

Table XI indicates that bullish analysts are significantly more likely to be called on earlier in a call; a one-standard deviation increase in RECD brings a questioner forward by about two tenths of a position in the queue. In addition, Table XI shows that All-Star 
analysts, affiliated analysts, and analysts from more prestigious brokerage firms are called on earlier in a call. Further, the interaction terms between the recommendation level and the status variables are all negative and significant, suggesting that bullish analysts with status are particularly likely to be called on earlier in a call. In sum, these results provide additional evidence on the extent to which firms manipulate the structure and content of their earnings calls.

\section{B. Types of Questions Asked}

To further assess the degree to which firms manage the information environment of the call, we explore the aggressiveness of the questions asked by the analysts called upon. If firms truly are trying to conceal negative information by calling on analysts less likely to uncover problematic information through their questioning, one might expect to see that the questions posed by favorable analysts are more favorable or less probing in some way. Gauging the difficulty of a question is obviously a nontrivial exercise without understanding the context in which a question is asked. We use a straightforward, but imperfect, measure, and hence view these results as merely suggestive. Specifically, we measure how "positive" each question is by the number of positive relative to negative words in an analyst's question using the Loughran and McDonald (2011) dictionary, which is constructed for financial contexts.

Appendix Table A5 shows the results examining aggressiveness of question. Columns 1 and 2 have as dependent variable the ratio of positive words relative to total coded words (\#positive + \#negative). Columns 3 and 4 use a slightly different specification, with the dependent variable being the log difference between the number of positive and negative words in the question. Columns 1-4 of Appendix Table A5 give a consistent message: those analysts who are called on during the call that are more favorable ask significantly more positive questions. In terms of magnitude, the coefficient of 0.031 $(t=2.82)$ implies that analysts with one notch higher recommendation (e.g., Buy vs. Hold), have $3.1 \%$ more positive words in their questions. 


\section{Discussion of Costs and Benefits of Casting for Firms and Analysts}

We conclude by briefly discussing a series of ancillary results that speak to the issue of the relative costs and benefits of casting for both the firms and the analysts.

\section{i. Potential Firm Benefits: Contemporaneous Investor Response}

We explore one potential benefit that firms receive by engaging in this type of behavior. Specifically, we investigate the investor response around the earnings call in which the firm is calling on more favorable analysts. If the firm is successful in preventing the flow of negative information by avoiding negative or cynical analysts, then the stock market response around the earnings call may be relatively positive. In Appendix Table A6 we test this idea by running Fama-Macbeth quarterly regressions of contemporaneous earnings announcement returns on the spread between recommendation levels of analysts in and out of the current call (RecIn-RecOut), plus a host of additional control variables (identical to Table V) including the magnitude of the earnings surprise itself.

Appendix Table A6 indicates that firms have significantly more positive abnormal returns around the call when they engage in casting behavior (i.e., call on more favorable analysts). In terms of magnitude, a one standard-deviation increase in (RecIn-RecOut) implies a $24 \%$ increase in the contemporaneous earnings announcement effect $\left(\mathrm{CAR}_{\mathrm{t}}\right)$. For robustness, we also compute an indicator variable equal to one if RecIn is greater than RecOut in quarter $t$ (RecIn>RecOut), which again captures the contemporaneous effect of casting on earnings announcement returns in that same quarter $t$. Columns 4-6 reveals that this indicator variable yields similar results as the continuous measure used in Columns 1-3. In fact, from Column 6, CARs are $41 \%$ higher in quarters where firms stage their conference calls (RecIn>RecOut), controlling for other determinants of earnings returns including the level of surprise itself.

\section{ii. Future Analyst Accuracy}

On the analyst side, we also explore if analysts who participate on the call are more accurate in their earnings forecasts in the future in our sample (see also Mayew (2008) and 
Mayew, Sharp, and Venkatachalam (2011) for similar evidence). To do so, we run panel regressions of future earnings forecast accuracy on a participation dummy, and a host of analyst- and firm-level characteristics. If an analyst was called on during a given call, the dummy equals one; otherwise the dummy is set to zero. We measure earnings forecast error in the next quarter $(t+1)$ in percentage terms as follows: [(absolute_value_of(actual earnings in quarter $t+1$ minus forecasted earnings in quarter $t+1)$ ), divided by lagged quarter $t-1$ price]. We include the same analyst- and firm-level controls as in Table II.

We run several different specifications of this basic test, and report the results in Appendix Table A7. For example, Columns 1-2 include firm-quarter fixed effects, and hence examine the relative accuracy of analysts covering the same firm (A is in stock X's call, and B is out of stock X's call). Then in Columns 3-4 we include analyst-quarter fixed effects, and hence examine the relative accuracy on stocks covered by the same analyst (A is in stock X's call, but is out of stock Y's call). Next in Columns 5-6 we include firmquarter fixed effects, and examine the relative accuracy of analysts on the same other firm (A is in stock X's call, but not in stock Y's call, and B is in neither; we examine A and B's forecast accuracy for stock Y). Columns 1-4 of Appendix Table A7 indicate that analysts participating in the call are more accurate in their next earnings forecast, both relative to other analysts on the same stock who do not participate, and relative to themselves on other stocks where they themselves do not participate. This finding is consistent with the idea that analysts receive some benefit to being able to receive answers to their own private questions. In terms of magnitude, the coefficient in Column 4 of $-0.028(t=2.80)$ suggests that being in the call reduces forecast error on the next earnings by $5.4 \%$ (of the average forecast error) relative to the other firms covered by the same analyst. Columns 5-6 confirm this, further showing only modest evidence that this benefit spills over to their accuracy on other stocks.

\section{iii. Future Changes in Analyst Coverage}

Lastly, we examine if there is a potential cost to firms of persistently casting their calls over time. Given that there is a benefit to firms in the form of higher contemporaneous earnings announcement returns, one might expect virtually all firms to engage in this 
behavior continuously. One possibility is that firms will lose analyst coverage over time, as analysts are unable to ask their own privately-valued questions (which lead to increases in future earnings accuracy as shown above in Appendix Table A7), and become unwilling to cover the firm. Analyst coverage is valuable to a firm as it potentially increases liquidity in the stock (see Irvine (2003) for evidence in favor of this idea).

We test this idea in Appendix Table A8 by running regressions of the change in analyst coverage on a measure of "persistent casting," defined as the average of (RecInRecOut) over the prior 4 quarters (or alternatively, as the fraction of quarters in which RecIn is greater than RecOut). The dependent variable is "post-coverage," defined as coverage after the event year during which we measure persistent casting. We also control for "pre-coverage," which is defined as coverage before the event year.

Appendix Table A8 shows that persistent casting predicts a significant decline in future analyst coverage. In terms of magnitude, the estimates in Column 4 (which uses the fraction of quarters in which RecIn>RecOut to define persistence) imply that an additional quarter of casting is associated with a 0.12 drop in analyst coverage the following year. In Appendix Table A9, we also show that, perhaps not surprisingly, it is the analysts who do not speak on the call that ultimately drop coverage.

\section{Conclusion}

In this paper we explore a subtle, but economically important way in which firms shape their information environments: through the specific organization and choreographing of earnings conference calls. Our analysis rests on a simple premise: firms have an information advantage, and they understand this and have the ability to be strategic in its release. Our key finding is that firms that organize their conference calls by calling on those analysts with the most optimistic views about their firm appear to be hiding bad news, which ultimately leaks out in the future. Specifically, we show that these "casting" firms experience negative returns when the hidden information is revealed in the future. A long-short portfolio that goes long the non-casting firms and short the casting firms around their subsequent calls earns abnormal returns ranging from 129 to 149 basis points per month, or almost 18 percent per year.

Playing Favorites - Page 29 
We demonstrate that firms with an ex-ante larger incentive to cast their calls, namely firms with higher discretionary accruals, firms that barely meet/exceed earnings expectations, and firms (and their executives) about to issue equity, sell shares, and exercise options, are all significantly more likely to do so.

We also provide out-of-sample evidence for the core findings in this paper, and show that the phenomenon of casting conference calls extends beyond the U.S., to an international sample including the United Kingdom, Canada, France, and Japan. Collectively, our data spans 5 countries, 13 years, 4101 firms, and 7125 analysts, covering 91,878 conference calls in total, making our dataset the largest and most extensive of any project analyzing corporate earnings calls. We estimate that between $17-22 \%$ of firms in a given quarter engage in this type of opportunistic behavior. However, it is not costless for firms to engage in casting their calls: firms who are frequent casters of their calls, see significant future drops in analyst coverage.

In sum, we provide new evidence on a channel through which firms influence information disclosure even in level-playing-field information environments. And while we have focused on a specific set of firm behaviors, there are likely many other ways in which firms seek to control information flow to the market. Our paper suggests that exploring these subtle but important mechanisms through which firms manipulate their information environments is a promising avenue for future research.

Playing Favorites - Page 30 


\section{References}

Agrawal, Anup, Sahiba Chadha and Mark A. Chen, 2006, Who is afraid of Reg FD? The behavior and performance of sell-side analysts following the SEC's Fair Disclosure Rules, Journal of Business 79, 2811-2834.

Beaver, William, 1968, The information content of annual earnings announcements, Journal of Accounting Research 6, 67-92.

Bergman, Nittai and Sugata Roychowdury, 2008, Investor Sentiment, Expectations, and Corporate Disclosure, Journal of Accounting Research 46, 1057-1083.

Chen, Shuping, and Dawn Matsumoto. 2006. Favorable versus unfavorable recommendations: The impact on analyst access to management-provided information, Journal of Accounting Research 40 (4): 657-689.

Chen, Shuping, Stephan Hollander, and Kelvin Law, 2014, The price of silence: When no one asks questions during conference calls, Working paper, University of Texas.

Cohen, Lauren, Andrea Frazzini, and Christopher Malloy, 2010. Sell side school ties, Journal of Finance 65, 1409-1437.

Cooper, Rick, Theodore Day, and Craig Lewis, 2001, Following the leader: A study of individual analysts' earnings forecasts, Journal of Financial Economics 61, 383-416.

Degeorge, Francois, Jayendu Patel, and Richard Zeckhauser, 1999. Earnings management to exceed thresholds, Journal of Business 72, 1-33.

DellaVigna, Stefano, and Joshua Pollet, 2009, Investor inattention and Friday earnings announcements, Journal of Finance 64, 109-749.

Diether, Karl B, Anna Scherbina, and Christopher Malloy, 2002, Differences of opinion and the cross-section of stock returns, Journal of Finance 57, 2113-2141.

Frazzini, Andrea, and Owen Lamont, 2006, The earnings announcement month premium and trading volume, Working paper, Yale University.

Gintschel, A. and S. Markov. 2004. The Effectiveness of Regulation FD. Journal of Accounting and Economics 37: 293-314.

Groysberg, Boris, Paul Healy, Craig Chapman, Devin Shanthikumar, and Yang Gui (2007), Do buy-side analysts out-perform the sell-side?, Working paper, Harvard University.

Hobson, Jessen, William J. Mayew, and Mohan Venkatachalam. 2012. Analyzing Speech to Detect Financial Misreporting, Journal of Accounting Research, 50 (2): 349-392.

Hollander, Stephan, Maarten Pronk, and Erik Roelofsen, 2010, Does Silence Speak? An 
Empirical Analysis of Disclosure Choices During Conference Calls, Journal of Accounting Research, Vol. 48, Issue 3, pp. 531-563.

Hirshleifer, David, Kewei Hou, and Siew Hong Teoh, 2012, The accruals anomaly: Risk or mispricing? Management Science 58, 320-335.

Hirshleifer, David, Sonya Lim, and Siew Hong Teoh, 2009, Driven to distraction: Extraneous events and underreaction to earnings news, Journal of Finance 64, 22892325.

Hong, Harrison, and Jeffrey D. Kubik, 2003, Analyzing the analysts: Career concerns and biased forecasts, Journal of Finance 58, 313-351.

Kinney, William, David Burgstahler and Roger Martin, 2002, Earnings Surprise "Materiality" as Measured by Stock Returns, Journal of Accounting Research 40, 1297-1329.

Kothari, SP, Susan Shu and Peter Wysocki, 2009, Do managers withhold bad news?, Journal of Accounting Research 47, 241-276.

Larcker, David, and Anastasia Zakolyukina, 2012, Detecting Deceptive Discussions in Conference Calls, Journal of Accounting Research, Vol. 50, Issue 2, pp. 495540.

Lin, Hsiou-wei and Maureen F. McNichols, 1998, Underwriting relationships, analysts' earnings forecasts and investment recommendations, Journal of Accounting and Economics 25, 101-127.

Lin, Hsiou-wei, Maureen F. McNichols, and Patricia O'Brien, 2005, Analyst impartiality and investment banking relationships, Journal of Accounting Research 43, 623-650.

Kumar, Alok, 2010, Self-selection and the forecasting abilities of female equity analysts, Journal of Accounting Research, 48, 393-435.

Matsumoto, Dawn, Maarten Pronk, and Erik Roelofsen, 2011, What Makes Conference Calls Useful? The Information Content of Managers Presentations and Analysts Discussion Sessions. The Accounting Review 86 (4), 1383-1414.

Mayew, W. 2008. Evidence of Management Discrimination Among Analysts During Earnings Conference Calls. Journal of Accounting Research 46 (3): 627-659.

Mayew, William J., and Mohan Venkatachalam. 2012, The Power of Voice: Managerial Affective States and Future Firm Performance, Journal of Finance, 67 (1): 1-43.

Mayew, W., N. Sharp, and M. Venkatachalam, 2013, Using Earnings Conference Calls to Identify Analysts with Superior Private Information, Review of Accounting Studies 18(2): 386-413. 
Michaely, Roni, and Kent L. Womack, 1999, Conflict of interest and the credibility of underwriter analyst recommendations, Review of Financial Studies 12, 653-686.

Mohanran, Partha and Shyam V. Sunder, 2006, How has Regulation FD affected the operations of financial analysts?, Contemporary Accounting Research 23, 49152

Niessner, Marina, 2013, Strategic disclosure timing and insider trading, Working paper, Yale University.

Sloan, R., 1996, Do stock prices fully reflect the information in accruals and cash flows about future earnings?, Accounting Review 71, 289-316.

Stickel, Scott, 1992, Reputation and performance among security analysts, Journal of Finance 47, 1811-1836.

Zhou, Dexin, 2014, The blame game, Working paper, Emory University. 


\section{Table I: Summary Statistics}

This table reports summary statistics of our sample. Panel A reports the key statistics of our US conference call sample (2003-2015), and Panel B reports the key statistics of our pooled international conference call sample (which includes Canada, UK, France, and Japan). \#(IN) is the number of sell-side analysts that have an opportunity to ask questions in a conference call (in-analysts), and \#(OUT) is the number of analysts that do not have the opportunity to ask questions in the conference call (out-analysts). $R E C D_{\text {in }}$ is the average recommendation level of an in-analyst in the year prior to the conference call, and $R E C D_{\text {out }}$ is the average recommendation level of an out-analyst in the same period. $R E C D(I N)-R E C D(O U T)$ is the difference between the average $R E C D_{\text {in }}$ and average $R E C D_{\text {out }}$ for each conference call, and is our main measure of firms' casting behavior. Finally, $C A R$ is the cumulative abnormal return in the five-day window surrounding the quarterly earnings announcement, $S U E$ is the standardized earnings surprise, defined as seasonally-adjusted quarterly earnings growth scaled by lagged stock price, and RESTATE is a dummy variable that takes the value of one if a firm restates its earnings in a quarter and zero otherwise. We report in the table below the mean, standard deviation, $1^{\text {st }}, 25^{\text {th }}, 50^{\text {th }}, 75^{\text {th }}$, and $99^{\text {th }}$ percentiles of the distribution of each variable.

\begin{tabular}{|c|c|c|c|c|c|c|c|c|}
\hline \multicolumn{9}{|c|}{ Panel A: US Firms } \\
\hline & No. Calls & Mean & Std Dev & $\mathrm{P} 1$ & Q1 & Median & Q3 & P99 \\
\hline \multicolumn{9}{|c|}{ Number of analysts in vs. out of each conference call } \\
\hline$\#(I N)$ & 83,685 & 3.73 & 2.50 & 1 & 2 & 3 & 5 & 11 \\
\hline$\#(O U T)$ & 83,685 & 6.20 & 5.04 & 1 & 3 & 5 & 8 & 24 \\
\hline \multicolumn{9}{|c|}{ Analyst recommendations } \\
\hline$R E C D_{\text {in }}$ & & 3.75 & 0.77 & 2.00 & 3.04 & 3.79 & 4.25 & 5.00 \\
\hline$R E C D_{\text {out }}$ & & 3.61 & 0.81 & 1.75 & 3.00 & 3.54 & 4.00 & 5.00 \\
\hline $\begin{array}{l}R E C D(I N)- \\
R E C D(O U T)\end{array}$ & & 0.15 & 0.61 & -1.40 & -0.22 & 0.13 & 0.50 & 1.71 \\
\hline \multicolumn{9}{|c|}{ Earnings Announcement Day Returns, Earnings Surprises } \\
\hline CAR & & 0.0040 & 0.1023 & -0.2660 & -0.0437 & 0.0027 & 0.0500 & 0.2870 \\
\hline SUE & & -0.0032 & 0.1979 & -0.3548 & -0.0046 & 0.0012 & 0.0060 & 0.2691 \\
\hline REST ATE & & 0.02 & 0.14 & 0 & 0 & 0 & 0 & 1 \\
\hline
\end{tabular}

\begin{tabular}{lcccccccc}
\hline \multicolumn{7}{c}{ Panel B: International Firms } \\
\hline Number of analysts in vs. out of each conference call \\
\hline$\#(I N)$ & 5,471 & 4.72 & 3.05 & 1 & 2 & 4 & 7 & 13 \\
$\#($ OUT $)$ & 5,471 & 14.42 & 9.84 & 1 & 6 & 13 & 21 & 43 \\
\hline Analyst recommendations & & & & & & & \\
\hline RECD & \\
RECD & 3.63 & 0.60 & 2.00 & 3.20 & 3.67 & 4.00 & 5.00 \\
RECD $($ IN $)-$ & 3.55 & 0.47 & 2.14 & 3.26 & 3.57 & 3.86 & 4.67 \\
RECD $($ OUT $)$ & 0.08 & 0.61 & -1.50 & -0.31 & 0.08 & 0.43 & 1.61 \\
\hline Earnings Announcement Day Returns & 0.0041 & 0.0713 & -0.1983 & -0.0299 & 0.0027 & 0.0413 & 0.2058 \\
\hline CAR &
\end{tabular}




\section{Table II: Firm Behavior on Conference Calls}

This table examines the likelihood of an analyst having an opportunity to ask a question in the conference call. The dependent variable in all columns is an indicator that takes the value of one if the analyst asks a question in the conference call and zero otherwise. Columns 1-4 conduct a panel OLS regression, and columns 5 and 6 conduct a pooled logit regression. The main independent variable in columns 1-4 is the average recommendation of the analyst in the year prior to the conference call $(R E C D)$, and that in columns 5 and 6 is the prior-year average recommendation of the analyst relative to the consensus recommendation $\left(R E C D^{a d j}\right)$. Analyst level controls include: the number of years the analyst has covered the firm (LENGTH), the number of years the analyst has been in the IBES database (CAREER), the number of stocks covered by the analyst, the number of stocks covered by the broker (a measure of broker size), whether the analyst is an all-star analyst, and whether the analyst is affiliated with a broker that underwrites for the firm in question. Firm level controls include: lagged market capitalization, book to market ratio, past one year stock returns, monthly share turnover in the previous year, daily idiosyncratic volatility in the previous year, number of analysts covering the firm, institutional ownership, and discretionary accruals. Columns 1 and 2 include firm* quarter fixed effects, and columns 3 and 4 include analyst*quarter fixed effects. Standard errors, clustered at both the firm and quarter level, are shown in parenthesis. ${ }^{*},{ }^{* *},{ }^{* *}$ denote significance at the $10 \%, 5 \%$, and $1 \%$ level, respectively.

\begin{tabular}{|c|c|c|c|c|c|c|}
\hline & $I N_{i, j, t}$ & $I N_{i, j, t}$ & $I N_{i, j, t}$ & $I N_{i, j, t}$ & $I N_{i, j, t}$ & $I N_{i, j, t}$ \\
\hline & {$[1]$} & {$[2]$} & {$[3]$} & {$[4]$} & {$[5]$} & {$[6]$} \\
\hline \multirow[t]{2}{*}{$R E C D_{i, j, t}$} & $0.057^{* * *}$ & $0.067^{* * *}$ & $0.070^{* * *}$ & $0.072^{* * *}$ & & \\
\hline & $(0.004)$ & $(0.004)$ & $(0.004)$ & $(0.004)$ & & \\
\hline \multirow[t]{2}{*}{$R E C D_{i, j, t}^{a d j}$} & & & & & $0.245^{* * *}$ & $0.295^{* * *}$ \\
\hline & & & & & $(0.018)$ & $(0.018)$ \\
\hline \multirow[t]{2}{*}{$L_{E N G T H_{j, t}}$} & & $0.031^{* * *}$ & & & & $0.082^{* * *}$ \\
\hline & & $(0.004)$ & & & & $(0.016)$ \\
\hline \multirow{2}{*}{$\operatorname{CAREER}_{j, t}$} & & $-0.016^{* * *}$ & & & & $-0.044^{* * *}$ \\
\hline & & $(0.003)$ & & & & $(0.013)$ \\
\hline \multirow{2}{*}{$\#$ STOCK $K_{j, t}^{\text {analyst }}$} & & -0.003 & & & & 0.011 \\
\hline & & $(0.004)$ & & & & $(0.018)$ \\
\hline \multirow{2}{*}{$\# S T O C K_{j, t}^{\text {broker }}$} & & $0.043^{* * *}$ & & & & $0.202^{* * *}$ \\
\hline & & $(0.002)$ & & & & $(0.010)$ \\
\hline \multirow[t]{2}{*}{$A L L S T A R_{j, t}$} & & $0.110^{* * *}$ & & & & $0.325^{* * *}$ \\
\hline & & $(0.007)$ & & & & $(0.030)$ \\
\hline \multirow[t]{2}{*}{$A F F I L I A T E_{j, t}$} & & $0.041^{* * *}$ & & & & $0.245^{* * *}$ \\
\hline & & $(0.009)$ & & & & $(0.031)$ \\
\hline Other Controls & No & No & No & Yes & No & Yes \\
\hline No Obs. & 832,262 & 832,262 & 832,262 & 832,262 & 832,262 & 832,262 \\
\hline Adj-/Pseudo $R^{2}$ & 0.025 & 0.054 & 0.362 & 0.366 & 0.005 & 0.025 \\
\hline
\end{tabular}




\section{Table III: Which Firms Call on More Favorable Analysts}

This table examines which firms call on more favorable analysts. Columns 1-3 relate the difference in average recommendation between analysts that ask questions in the conference call and those that do not to a host of firm characteristics, and columns 4-7 analyze whether this recommendation differential forecasts subsequent selling behavior of company shares. The dependent variable in the first three columns is the lagged difference in average prior-year recommendations between in-analysts and out-analysts $(R E C D(I N)$ $R E C D(O U T))$. The dependent variable in column 4 is an indicator that equals one if the firm has at least one seasoned equity offering in the following quarter and zero otherwise; that in column 5 is an indicator that equals one if the firm has positive net insider selling in the following quarter and zero otherwise; that in column 6 is an indicator that equals one if top executives exercise their stock options in the following quarter and zero otherwise; and that in column 7 is an indicator that equals one if top executives receive option grants in the following quarter and zero otherwise. The main independent variable in columns 4-7 is lagged $R E C D(I N)-R E C D(O U T)$. Other independent variables include: a dummy (SUE0)that equals one if the firm has a zero or one cent earnings surprise and zero otherwise, discretionary accruals, analyst forecast dispersion and recommendation dispersion, institutional ownership, the number of analysts covering the firm, and idiosyncratic volatility. Other control variables include: lagged market capitalization, book to market ratio, past one year stock returns, average stock recommendation, and past one year monthly share turnover. Columns 1-3 conduct a pooled OLS regression with both firm and quarter fixed effects. Columns 4-7 conduct a logit regression. Standard errors, clustered at both the firm and quarter level, are shown in parenthesis. ${ }^{*}, * *, * * *$ denote significance at the $10 \%, 5 \%$, and $1 \%$ level, respectively.

\begin{tabular}{|c|c|c|c|c|c|c|c|}
\hline & \multicolumn{3}{|c|}{$R E C D(I N)_{i, t}-R E C D(O U T)_{i, t}$} & \multirow{2}{*}{$\frac{S E O_{i, t+1}}{[4]}$} & \multirow{2}{*}{$\frac{I N S I D E R_{i, t+1}}{[5]}$} & \multirow{2}{*}{$\begin{array}{c}\text { EXERCISE } E_{i, t+1} \\
{[6]}\end{array}$} & \multirow{2}{*}{$\begin{array}{c}G R A N T_{i, t+1} \\
{[7]}\end{array}$} \\
\hline & {$[1]$} & {$[2]$} & {$[3]$} & & & & \\
\hline $\operatorname{RECD}(I N)_{i, t}-$ & & & & $0.076^{* *}$ & $0.044^{* *}$ & $0.032^{*}$ & $-0.045^{* *}$ \\
\hline$R E C D(O U T)_{i, t}$ & & & & $(0.036)$ & $(0.020)$ & $(0.019)$ & $(0.022)$ \\
\hline \multirow[t]{2}{*}{$S U E 0_{i, t}$} & $0.030^{* *}$ & $0.027^{* *}$ & $0.027^{* *}$ & 0.010 & $-0.114^{* * *}$ & $-0.117^{* * *}$ & -0.029 \\
\hline & $(0.013)$ & $(0.013)$ & $(0.013)$ & $(0.100)$ & $(0.043)$ & $(0.042)$ & $(0.048)$ \\
\hline \multirow[t]{2}{*}{$A C C R U A L_{i, t}$} & $0.139 * *$ & $0.104^{*}$ & $0.100^{*}$ & $2.208^{* * *}$ & $0.425^{*}$ & 0.293 & $-0.576^{* *}$ \\
\hline & $(0.054)$ & $(0.054)$ & $(0.054)$ & $(0.349)$ & $(0.243)$ & $(0.273)$ & $(0.273)$ \\
\hline \multirow[t]{2}{*}{$F_{C S T D I S P} P_{i, t}$} & & -0.014 & -0.002 & 0.155 & $-0.349^{* * *}$ & $-0.495^{* * *}$ & -0.049 \\
\hline & & $(0.040)$ & $(0.033)$ & $(0.276)$ & $(0.114)$ & $(0.127)$ & -0.031 \\
\hline \multirow[t]{2}{*}{$R E C D D I S P_{i, t}$} & & $0.194^{* * *}$ & $0.192^{* * *}$ & -0.053 & 0.023 & 0.043 & $0.348^{* * *}$ \\
\hline & & $(0.020)$ & $(0.020)$ & $(0.097)$ & $(0.060)$ & $(0.071)$ & $(0.073)$ \\
\hline \multirow[t]{2}{*}{$\operatorname{INSTOWN}_{i, t}$} & & -0.004 & -0.004 & $-0.488^{* * *}$ & $0.421^{* * *}$ & $0.315^{* * *}$ & $0.670^{* * *}$ \\
\hline & & $(0.014)$ & $(0.015)$ & $(0.133)$ & $(0.086)$ & $(0.077)$ & $(0.111)$ \\
\hline \multirow[t]{2}{*}{$\# A N A L Y S T_{i, t}$} & & $-0.004^{* * *}$ & $-0.004^{* * *}$ & $-0.019^{* *}$ & 0.005 & -0.002 & $-0.020^{* * *}$ \\
\hline & & $(0.001)$ & $(0.001)$ & $(0.008)$ & $(0.005)$ & $(0.005)$ & $(0.005)$ \\
\hline \multirow[t]{2}{*}{$I^{D I O V O L} L_{i, t}$} & & 0.323 & 0.353 & $0.345^{* * *}$ & $-0.165^{* * *}$ & $-0.245^{* * *}$ & 0.033 \\
\hline & & $(0.492)$ & $(0.493)$ & $(0.584)$ & $(0.044)$ & $(0.040)$ & $(0.049)$ \\
\hline Other Controls & No & No & Yes & Yes & Yes & Yes & Yes \\
\hline No Obs. & 66,357 & 66,357 & 66,357 & 66,357 & 66,357 & 66,357 & 66,357 \\
\hline Adj-/Pseudo R ${ }^{2}$ & 0.101 & 0.128 & 0.129 & 0.103 & 0.081 & 0.075 & 0.039 \\
\hline
\end{tabular}


Table IV: Distribution of RecIn-RecOut by Year

Panel A reports the mean, standard deviation, $1^{\text {st }}, 25^{\text {th }}, 50^{\text {th }}, 75^{\text {th }}$, and $99^{\text {th }}$ percentiles of the distribution of $R E C D(I N)-R E C D(O U T)$ by year. Panel $\mathrm{B}$ reports the fraction of RECD (IN) - RECD(OUT) greater than a certain threshold in each year.

\begin{tabular}{|c|c|c|c|c|c|c|c|c|}
\hline \multicolumn{9}{|c|}{ Panel A: Distribution of $R E C D(I N)-R E C D(O U T)$ by Year } \\
\hline Year & No. Obs & Mean & StdDev & $1 \%$ & $25 \%$ & $50 \%$ & $75 \%$ & $99 \%$ \\
\hline 2003 & 3,579 & 0.123 & 0.553 & -1.389 & -0.215 & 0.123 & 0.462 & 1.497 \\
\hline 2004 & 4,984 & 0.186 & 0.617 & -1.322 & -0.189 & 0.158 & 0.545 & 1.842 \\
\hline 2005 & 6,022 & 0.165 & 0.640 & -1.458 & -0.217 & 0.151 & 0.542 & 1.817 \\
\hline 2006 & 6,757 & 0.163 & 0.639 & -1.393 & -0.215 & 0.138 & 0.521 & 1.883 \\
\hline 2007 & 7,307 & 0.147 & 0.631 & -1.500 & -0.225 & 0.105 & 0.521 & 1.750 \\
\hline 2008 & 7,799 & 0.169 & 0.613 & -1.396 & -0.196 & 0.142 & 0.535 & 1.741 \\
\hline 2009 & 8,047 & 0.134 & 0.603 & -1.361 & -0.239 & 0.110 & 0.500 & 1.659 \\
\hline 2010 & 7,879 & 0.134 & 0.599 & -1.399 & -0.228 & 0.119 & 0.499 & 1.658 \\
\hline 2011 & 7,675 & 0.143 & 0.603 & -1.405 & -0.223 & 0.131 & 0.500 & 1.667 \\
\hline 2012 & 7,702 & 0.148 & 0.592 & -1.361 & -0.202 & 0.137 & 0.484 & 1.741 \\
\hline 2013 & 7,418 & 0.135 & 0.581 & -1.306 & -0.211 & 0.125 & 0.477 & 1.625 \\
\hline 2014 & 7,201 & 0.124 & 0.583 & -1.393 & -0.211 & 0.122 & 0.458 & 1.633 \\
\hline 2015 & 1,315 & 0.128 & 0.609 & -1.542 & -0.232 & 0.155 & 0.493 & 1.637 \\
\hline 2003-2015 & 83,685 & 0.147 & 0.606 & -1.400 & -0.2 & 0.129 & 0.500 & 1.708 \\
\hline Pane & 1 B: Fracti & $\mathrm{n}$ of $R E C L$ & $D(I N)-R$ & $C D(O U 1$ & Grea & ter Than So & me Thresl & \\
\hline Year & No. Obs & $\%>0$ & $\%>$ & $\%$ & 0.4 & $\%>0.6$ & $\%>0.8$ & $\%>1$ \\
\hline 2003 & 3,579 & $59.49 \%$ & 44.12 & & & $17.71 \%$ & $10.31 \%$ & $4.89 \%$ \\
\hline 2004 & 4,984 & $62.70 \%$ & 46.77 & & & $22.45 \%$ & $14.55 \%$ & $8.61 \%$ \\
\hline 2005 & 6,022 & $60.48 \%$ & 46.28 & 32 & & $22.39 \%$ & $14.25 \%$ & $8.75 \%$ \\
\hline 2006 & 6,757 & $59.94 \%$ & 45.43 & & & $21.86 \%$ & $14.33 \%$ & $8.97 \%$ \\
\hline 2007 & 7,307 & $57.73 \%$ & 43.93 & & & $21.54 \%$ & $14.07 \%$ & $8.47 \%$ \\
\hline 2008 & 7,799 & $60.61 \%$ & 46.02 & 32 & & $21.84 \%$ & $14.07 \%$ & $8.27 \%$ \\
\hline 2009 & 8,047 & $58.05 \%$ & 43.53 & 30. & & $20.12 \%$ & $12.84 \%$ & $7.41 \%$ \\
\hline 2010 & 7,879 & $59.32 \%$ & 44.36 & 30. & $5 \%$ & $19.51 \%$ & $11.84 \%$ & $7.21 \%$ \\
\hline 2011 & 7,675 & $59.70 \%$ & 45.17 & 31. & $2 \%$ & $20.22 \%$ & $12.83 \%$ & $7.48 \%$ \\
\hline 2012 & 7,702 & $60.17 \%$ & 45.17 & 31. & $6 \%$ & $18.54 \%$ & $11.82 \%$ & $7.02 \%$ \\
\hline 2013 & 7,418 & $59.57 \%$ & 43.83 & 29 . & $3 \%$ & $19.20 \%$ & $11.26 \%$ & $6.44 \%$ \\
\hline 2014 & 7,201 & $58.98 \%$ & 43.80 & 28. & & $17.83 \%$ & $11.14 \%$ & $5.97 \%$ \\
\hline 2015 & 1,315 & $59.24 \%$ & 46.08 & 31. & & $18.40 \%$ & $11.48 \%$ & $6.24 \%$ \\
\hline 2003-2015 & 83,685 & $59.63 \%$ & 44.84 & 31 . & & $20.24 \%$ & $12.78 \%$ & $7.49 \%$ \\
\hline
\end{tabular}




\section{Table V: Future Earnings Announcement Returns and Earnings Surprises}

Panel A reports forecasting regressions of earnings announcement day returns and earnings surprises on lagged differences in average recommendations between analysts that ask questions in the conference call and those that do not. The dependent variable in columns 1-3 is the cumulative abnormal return in the five-day window around the earnings announcement (CAR, in \%) and that in columns 4-6 is the standardized unexpected earnings, defined as seasonally adjusted quarterly earnings growth scaled by lagged stock price (SUE, in \%). Both dependent variables are measured in the subsequent quarter. The main independent variable across all columns is the lagged difference in average prior-year recommendations between inanalysts and out-analysts $(R E C D(I N)-R E C D(O U T))$. We also include in the regression lagged analyst forecast dispersion, analyst recommendation dispersion, institutional ownership, number of analysts covering the firm, an SEO dummy that equals one if the firm has at least one seasoned equity offering in the current quarter and zero otherwise, an INSIDER dummy that equals one if the firm has net insider selling in the current quarter and zero otherwise, an EXCERISE dummy that equals one if top executives exercise their stock options in the current quarter and zero otherwise. Other control variables include: lagged market capitalization, book to market ratio, past one year stock returns, monthly share turnover, idiosyncratic volatility, average stock recommendation, and discretionary accruals. Panel B reports the results of similar forecasting regressions, where we also include a NOMOREQUES dummy (which takes the value of one if there is no more question in the queue at the end of the conference call and zero otherwise), as well as its interaction with $\operatorname{RECD}(I N)-\operatorname{RECD}(O U T)$. In both panels, we conduct Fama-MacBeth regression with Newey-West adjusted standard errors of four lags. ${ }^{*},{ }^{* *}, * * *$ denote significance at the $10 \%$, $5 \%$, and $1 \%$ level, respectively.

\begin{tabular}{|c|c|c|c|c|c|c|}
\hline \multicolumn{7}{|c|}{ Panel A: Forecasting Future Announcement Returns and Earnings Surprises } \\
\hline & $C A R_{i, t+1}$ & $C A R_{i, t+1}$ & $C A R_{i, t+1}$ & $S U E_{i, t+1}$ & $S U E_{i, t+1}$ & $S U E_{i, t+1}$ \\
\hline & {$[1]$} & {$[2]$} & {$[3]$} & {$[4]$} & {$[5]$} & {$[6]$} \\
\hline $\operatorname{RECD}(I N)_{i, t}-$ & $-0.244^{* * *}$ & $-0.190^{* * *}$ & $-0.259^{* * *}$ & $-0.370^{* *}$ & $-0.268^{* *}$ & $-0.269^{* *}$ \\
\hline$R E C D(O U T)_{i, t}$ & $(0.081)$ & $(0.073)$ & $(0.098)$ & $(0.158)$ & $(0.136)$ & $(0.139)$ \\
\hline \multirow[t]{2}{*}{ FCSTDISP $_{i, t}$} & & 0.256 & 0.117 & & -0.484 & -0.371 \\
\hline & & $(0.612)$ & $(0.390)$ & & (1.328) & $(1.274)$ \\
\hline \multirow{2}{*}{$\operatorname{RECDDISP}_{i, t}$} & & -0.290 & -0.290 & & -0.340 & $-0.750^{*}$ \\
\hline & & $(0.215)$ & $(0.228)$ & & $(0.415)$ & $(0.428)$ \\
\hline \multirow[t]{2}{*}{$\operatorname{INSTOWN}_{i, t}$} & & $0.470^{* * *}$ & $0.481^{* * *}$ & & -0.174 & -0.269 \\
\hline & & $(0.129)$ & $(0.111)$ & & $(0.388)$ & $(0.566)$ \\
\hline \multirow[t]{2}{*}{$\# A N A L Y S T_{i, t}$} & & 0.026 & 0.200 & & 0.243 & $-0.463^{* * *}$ \\
\hline & & $(0.100)$ & $(0.140)$ & & $(0.295)$ & $(0.162)$ \\
\hline \multirow[t]{2}{*}{$S E O_{i, t}$} & & & -0.585 & & & 0.899 \\
\hline & & & $(0.263)$ & & & $(0.930)$ \\
\hline \multirow[t]{2}{*}{$I N S I D E R_{i, t}$} & & & -0.075 & & & 0.147 \\
\hline & & & $(0.179)$ & & & $(0.174)$ \\
\hline \multirow[t]{2}{*}{ EXERCISE $_{i, t}$} & & & 0.199 & & & $0.223^{* *}$ \\
\hline & & & $(0.133)$ & & & $(0.090)$ \\
\hline Other Controls & No & No & Yes & No & No & Yes \\
\hline No Quarters & 49 & 49 & 49 & 49 & 49 & 49 \\
\hline Adj-R $R^{2}$ & 0.003 & 0.014 & 0.050 & 0.020 & 0.120 & 0.158 \\
\hline
\end{tabular}


Table V (ctd.): Future Earnings Surprises and Earnings Announcement Returns

\begin{tabular}{|c|c|c|c|c|c|c|}
\hline \multicolumn{7}{|c|}{ Panel B: Interaction with the NoMoreQues Dummy } \\
\hline & $C A R_{i, t+1}$ & $C A R_{i, t+1}$ & $C A R_{i, t+1}$ & $S U E_{i, t+1}$ & $S U E_{i, t+1}$ & $S U E_{i, t+1}$ \\
\hline & [1] & {$[2]$} & {$[3]$} & {$[4]$} & [5] & {$[6]$} \\
\hline $\operatorname{RECD}(I N)_{i, t}-$ & $-0.359 * * *$ & $-0.270^{* * *}$ & $-0.347^{* * *}$ & $-0.652^{* * *}$ & $-0.556^{* *}$ & $-0.620^{* * *}$ \\
\hline$R E C D(O U T)_{i, t}$ & $(0.105)$ & $(0.094)$ & $(0.108)$ & $(0.234)$ & $(0.227)$ & $(0.252)$ \\
\hline \multirow[t]{2}{*}{ INTERACT $_{i, t}$} & $0.235^{* *}$ & $0.198^{*}$ & $0.220^{* *}$ & $0.638^{* *}$ & $0.663^{* *}$ & $0.796^{* *}$ \\
\hline & $(0.105)$ & $(0.104)$ & $(0.105)$ & $(0.242)$ & $(0.325)$ & $(0.352)$ \\
\hline \multirow[t]{2}{*}{ NOMOREQUES $S_{i, t}$} & -0.221 & -0.249 & -0.265 & 0.365 & 0.370 & 0.489 \\
\hline & $(0.154)$ & $(0.183)$ & $(0.161)$ & $(0.357)$ & $(0.401)$ & $(0.305)$ \\
\hline \multirow{2}{*}{ FCSTDISP $_{i, t}$} & & 0.306 & 0.164 & & -0.488 & -0.374 \\
\hline & & $(0.672)$ & $(0.442)$ & & $(1.328)$ & $(1.274)$ \\
\hline \multirow[t]{2}{*}{$R E C D D I S P_{i, t}$} & & -0.241 & -0.216 & & -0.333 & $-0.739^{*}$ \\
\hline & & $(0.183)$ & $(0.174)$ & & $(0.414)$ & $(0.425)$ \\
\hline \multirow[t]{2}{*}{ INSTOWN $_{i, t}$} & & $0.484^{* * *}$ & $0.464^{* * *}$ & & -0.177 & -0.260 \\
\hline & & $(0.118)$ & $(0.116)$ & & $(0.391)$ & $(0.564)$ \\
\hline \multirow[t]{2}{*}{$\# A N A L Y S T_{i, t}$} & & -0.051 & 0.119 & & 0.313 & $-0.420^{* * *}$ \\
\hline & & $(0.122)$ & $(0.129)$ & & $(0.349)$ & $(0.162)$ \\
\hline \multirow[t]{2}{*}{$S E O_{i, t}$} & & & $-0.583^{* *}$ & & & 0.887 \\
\hline & & & $(0.270)$ & & & $(0.927)$ \\
\hline \multirow[t]{2}{*}{$I N S I D E R_{i, t}$} & & & -0.038 & & & 0.154 \\
\hline & & & $(0.149)$ & & & $(0.178)$ \\
\hline \multirow[t]{2}{*}{ EXERCISE $_{i, t}$} & & & 0.182 & & & $0.213^{* *}$ \\
\hline & & & $(0.119)$ & & & $(0.092)$ \\
\hline Other Controls & No & No & Yes & No & No & Yes \\
\hline No Quarters & 49 & 49 & 49 & 49 & 49 & 49 \\
\hline Adj-R ${ }^{2}$ & 0.009 & 0.022 & 0.055 & 0.022 & 0.122 & 0.160 \\
\hline
\end{tabular}




\section{Table VI: Future Earnings Announcement Returns to Extreme Casting}

This table reports forecasting regressions of earnings announcement day returns on lagged differences in average recommendations between analysts that ask questions in the conference call and those that do not. The dependent variable in all columns is the cumulative abnormal return in the five day window around the subsequent earnings announcement $(C A R$, in \%). The main independent variable in columns 1-3 is a dummy that equals one if $R E C D(I N)-R E C D(O U T)$ is greater than the $75^{\text {th }}$ percentile of its distribution in each quarter; the main independent variable in columns 4-6 is a dummy that equals one if $R E C D(I N)-$ $R E C D(O U T)$ is greater than the $90^{\text {th }}$ percentile of its distribution in each quarter. We include in the regressions the same set of control variables as in Table V. Columns 1 and 4 report the baseline result. Columns 2, 3, 5 and 6 further include a NOMOREQUES dummy (which takes the value of one if there is no more question in the queue at the end of the conference call and zero otherwise), as well as its interaction with the indicator based on $\operatorname{RECD}(I N)-\operatorname{RECD}(O U T)$. In each column, we conduct a Fama-MacBeth regression with Newey-West adjusted standard errors of four lags. *, **, *** denote significance at the $10 \%$, $5 \%$, and $1 \%$ level, respectively.

\begin{tabular}{|c|c|c|c|c|c|c|}
\hline & $C A R_{t+1}$ & $C A R_{t+1}$ & $C A R_{t+1}$ & $C A R_{t+1}$ & $C A R_{t+1}$ & $C A R_{t+1}$ \\
\hline & & \multicolumn{2}{|c|}{ CASTING $>75 \%$} & \multicolumn{3}{|c|}{ CASTING $>90 \%$} \\
\hline & {$[1]$} & {$[2]$} & {$[3]$} & {$[4]$} & {$[5]$} & {$[6]$} \\
\hline $\operatorname{RECD}(I N)_{i, t}-$ & $-0.219^{* *}$ & $-0.291^{* *}$ & $-0.327^{* *}$ & $-0.300^{* *}$ & $-0.487 * * *$ & $-0.430^{* * *}$ \\
\hline$R E C D(O U T)_{i, t}$ & $(0.094)$ & $(0.133)$ & $(0.151)$ & $(0.120)$ & $(0.161)$ & $(0.155)$ \\
\hline \multirow{2}{*}{$I_{N T E R A C T} T_{i, t}$} & & $0.155^{* *}$ & $0.187^{* *}$ & & $0.510^{* * *}$ & $0.435^{* *}$ \\
\hline & & $(0.077)$ & $(0.079)$ & & $(0.175)$ & $(0.196)$ \\
\hline \multirow[t]{2}{*}{ NOMOREQUES $S_{i, t}$} & & -0.230 & $-0.291^{*}$ & & -0.237 & $-0.283^{*}$ \\
\hline & & $(0.162)$ & $(0.173)$ & & $(0.158)$ & $(0.159)$ \\
\hline \multirow{2}{*}{$F C S T D I S P_{i, t}$} & & & 0.158 & & & 0.327 \\
\hline & & & $(0.431)$ & & & $(0.590)$ \\
\hline \multirow[t]{2}{*}{$R E C D D I S P_{i, t}$} & & & -0.222 & & & -0.274 \\
\hline & & & $(0.187)$ & & & $(0.220)$ \\
\hline \multirow[t]{2}{*}{ INSTOWN $_{i, t}$} & & & $0.473^{* * *}$ & & & $0.444^{* * *}$ \\
\hline & & & $(0.112)$ & & & $(0.118)$ \\
\hline \multirow[t]{2}{*}{$\# A N A L Y S T_{i, t}$} & & & 0.113 & & & 0.094 \\
\hline & & & $(0.133)$ & & & $(0.137)$ \\
\hline \multirow[t]{2}{*}{$S E O_{i, t}$} & & & $-0.572^{* *}$ & & & $-0.589 * *$ \\
\hline & & & $(0.266)$ & & & $(0.269)$ \\
\hline \multirow[t]{2}{*}{$I_{N S I D E R} R_{i, t}$} & & & -0.047 & & & -0.041 \\
\hline & & & $(0.156)$ & & & $(0.147)$ \\
\hline \multirow{2}{*}{$E X E R C I S E_{i, t}$} & & & 0.200 & & & 0.174 \\
\hline & & & $(0.131)$ & & & $(0.113)$ \\
\hline Other Controls & No & No & Yes & No & No & Yes \\
\hline F-M \# Qtrs & 49 & 49 & 49 & 49 & 49 & 49 \\
\hline Adj- $R^{2}$ & 0.003 & 0.009 & 0.056 & 0.003 & 0.008 & 0.055 \\
\hline
\end{tabular}




\section{Table VII: Portfolio Approach}

This table reports monthly returns to a calendar-time portfolio that exploits the return predictability of recommendation differentials between analysts that ask questions in the conference call and those that do not. Specifically, on each day, we rank all firms into five quintiles based on the recommendation differential between in-analysts and out-analysts in the previous quarter. Next, in the five days surrounding the following quarterly earnings announcement, we go long stocks whose RECD(IN)-RECD(OUT) in the previous quarter is in the top quintile, and short stocks whose $R E C D(I N)-R E C D(O U T)$ in the previous quarter is in the bottom quintile. If on any given day, there are fewer than 5 stocks in either the long or short lag, we hold the 30-day Treasury bill instead (this is the case for less than $10 \%$ of the trading days). We then aggregate these daily returns to the monthly level. Panel A reports the monthly returns to the five quintile portfolios after adjusting for various risk factors; and Panel B reports the risk exposures of these five portfolios. In the full specification, we control for the Carhart four factors (including momentum) and the liquidity factor. T-statistics, with Newey-West adjustments of four lags, are shown in brackets. Estimates significant at the $5 \%$ level are indicated in bold.

\begin{tabular}{cccccc}
\hline \multicolumn{7}{c}{ Panel A: Portfolio Returns } \\
\hline \multirow{2}{*}{ Quintile } & $\begin{array}{c}\text { Excess } \\
\text { Returns }\end{array}$ & $\begin{array}{c}\text { 1-Factor } \\
\text { Alpha }\end{array}$ & $\begin{array}{c}\text { 3-Factor } \\
\text { Alpha }\end{array}$ & $\begin{array}{c}\text { 4-Factor } \\
\text { Alpha }\end{array}$ & $\begin{array}{c}\text { 5-Factor } \\
\text { Alpha }\end{array}$ \\
\hline \multirow{2}{*}{1} & $1.46 \%$ & $1.08 \%$ & $1.07 \%$ & $1.07 \%$ & $1.03 \%$ \\
& {$[2.59]$} & {$[1.80]$} & {$[1.88]$} & {$[1.85]$} & {$[1.62]$} \\
\multirow{2}{*}{2} & $1.26 \%$ & $0.91 \%$ & $0.86 \%$ & $0.90 \%$ & $0.90 \%$ \\
& {$[2.55]$} & {$[1.65]$} & {$[1.65]$} & {$[1.72]$} & {$[1.54]$} \\
\multirow{2}{*}{3} & $0.96 \%$ & $0.39 \%$ & $0.35 \%$ & $0.36 \%$ & $0.37 \%$ \\
& {$[1.87]$} & {$[0.85]$} & {$[0.77]$} & {$[0.80]$} & {$[0.76]$} \\
\multirow{2}{*}{4} & $0.48 \%$ & $-0.13 \%$ & $-0.19 \%$ & $-0.20 \%$ & $-0.30 \%$ \\
& {$[0.75]$} & {$[-0.20]$} & {$[-0.31]$} & {$[-0.32]$} & {$[-0.46]$} \\
\multirow{2}{*}{5} & $0.18 \%$ & $-0.43 \%$ & $-0.39 \%$ & $-0.38 \%$ & $-0.44 \%$ \\
& {$[0.30]$} & {$[-0.69]$} & {$[-0.65]$} & {$[-0.63]$} & {$[-0.66]$} \\
\hline \multirow{2}{*}{$5-1$} & $-1.29 \%$ & $-1.53 \%$ & $-1.48 \%$ & $-1.47 \%$ & $-1.49 \%$ \\
& {$[-2.59]$} & {$[-2.86]$} & {$[-2.78]$} & {$[-2.78]$} & {$[-2.64]$} \\
\hline
\end{tabular}

\begin{tabular}{cccccccc}
\hline \multicolumn{7}{c}{ Panel B: Factor Loadings } \\
\hline & XRet & Alpha & MKT & SMB & HML & UMD & LIQ \\
\hline \multirow{2}{*}{1} & $1.46 \%$ & $1.03 \%$ & 0.175 & 0.742 & 0.448 & 0.014 & 0.078 \\
& {$[2.59]$} & {$[1.62]$} & {$[0.87]$} & {$[2.77]$} & {$[2.01]$} & {$[0.13]$} & {$[0.48]$} \\
5 & $0.18 \%$ & $-0.44 \%$ & 0.468 & 0.324 & 0.556 & -0.055 & 0.119 \\
& {$[0.30]$} & {$[-0.66]$} & {$[2.13]$} & {$[1.30]$} & {$[2.17]$} & {$[-0.54]$} & {$[0.64]$} \\
\hline $5-1$ & $-1.29 \%$ & $-1.49 \%$ & 0.304 & -0.403 & 0.128 & -0.066 & 0.049 \\
& {$[-2.59]$} & {$[-2.64]$} & {$[1.77]$} & {$[-1.78]$} & {$[0.43]$} & {$[-0.67]$} & {$[0.37]$} \\
\hline
\end{tabular}




\section{Table VIII: Future Earnings Restatements}

This table reports logit regressions of earnings restatements on the lagged difference in average recommendations between analysts that ask questions in the conference call and those that do not. The dependent variable in all columns is a RESTATE dummy that equals one if the firm restates its earnings in the following year and zero otherwise. The main independent variable is the lagged difference in average prior-year recommendations between in-analysts and out-analysts $(\operatorname{RECD}(I N)-\operatorname{RECD}(O U T))$. We also include in the regression lagged analyst forecast dispersion, analyst recommendation dispersion, institutional ownership, number of analysts covering the firm, an SEO dummy that equals one if the firm has at least one seasoned equity offering in the current quarter and zero otherwise, an INSIDER dummy that equals one if the firm has net insider selling in the current quarter and zero otherwise, an EXCERISE dummy that equals one if top executives exercise their stock options in the current quarter and zero otherwise. Other control variables include: lagged market capitalization, book to market ratio, past one year stock returns, monthly share turnover, idiosyncratic volatility, average stock recommendation, and discretionary accruals. In each column, we conduct a pooled logit regression. Columns 1-3 report the baseline results. Columns 46 further include a NOMOREQUES dummy (which takes the value of one if there is no more question in the queue at the end of the conference call and zero otherwise), as well as its interaction with $R E C D(I N)-$ $R E C D(O U T)$. Standard errors, clustered at the quarterly level, are reported in parenthesis. ${ }^{*},{ }^{*},{ }^{* * *}$ denote significance at the $10 \%, 5 \%$, and $1 \%$ level, respectively.

\begin{tabular}{|c|c|c|c|c|c|c|}
\hline \multicolumn{7}{|c|}{ Dependent Variable $=R E S T A T E_{i, t+1}$} \\
\hline & {$[1]$} & {$[2]$} & {$[3]$} & {$[4]$} & {$[5]$} & {$[6]$} \\
\hline $\operatorname{RECD}(I N)_{i, t}-$ & $0.067^{* *}$ & $0.057^{* *}$ & $0.056^{*}$ & $0.137^{* * *}$ & $0.123^{* * *}$ & $0.122^{* * *}$ \\
\hline$R E C D(O U T)_{i, t}$ & $(0.030)$ & $(0.029)$ & $(0.029)$ & $(0.036)$ & $(0.035)$ & $(0.035)$ \\
\hline \multirow[t]{2}{*}{ INTERACT $_{i, t}$} & & & & $-0.176^{* * *}$ & $-0.166^{* * *}$ & $-0.165^{* * *}$ \\
\hline & & & & $(0.062)$ & $(0.060)$ & $(0.060)$ \\
\hline \multirow[t]{2}{*}{ NOMOREQUES $S_{i, t}$} & & & & 0.056 & -0.007 & -0.008 \\
\hline & & & & $(0.049)$ & $(0.048)$ & $(0.048)$ \\
\hline \multirow[t]{2}{*}{$F C S T D I S P_{i, t}$} & & -0.069 & -0.098 & & -0.072 & -0.102 \\
\hline & & $(1.811)$ & $(1.785)$ & & $(1.815)$ & $(1.791)$ \\
\hline \multirow{2}{*}{$R E C D D I S P_{i, t}$} & & -0.018 & -0.021 & & -0.017 & -0.020 \\
\hline & & $(0.102)$ & $(0.102)$ & & $(0.102)$ & $(0.102)$ \\
\hline \multirow[t]{2}{*}{ INSTOWN $_{i, t}$} & & 0.005 & 0.010 & & 0.004 & 0.009 \\
\hline & & $(0.091)$ & $(0.091)$ & & $(0.091)$ & $(0.091)$ \\
\hline \multirow[t]{2}{*}{$\# A N A L Y S T_{i, t}$} & & $-0.146^{* * *}$ & $-0.145^{* * *}$ & & $-0.150^{* * *}$ & $-0.149^{* * *}$ \\
\hline & & $(0.033)$ & $(0.034)$ & & $(0.033)$ & $(0.034)$ \\
\hline \multirow[t]{2}{*}{$S E O_{i, t}$} & & & $0.243^{* *}$ & & & $0.241^{* *}$ \\
\hline & & & $(0.097)$ & & & $(0.097)$ \\
\hline \multirow[t]{2}{*}{$I_{N S I D E R} R_{i, t}$} & & & 0.059 & & & 0.059 \\
\hline & & & $(0.050)$ & & & $(0.050)$ \\
\hline \multirow[t]{2}{*}{$\operatorname{EXERCISE}_{i, t}$} & & & $-0.081^{*}$ & & & $-0.081^{*}$ \\
\hline & & & $(0.049)$ & & & $(0.049)$ \\
\hline Other Controls & No & No & Yes & No & No & Yes \\
\hline No Obs. & 53,409 & 53,409 & 53,409 & 53,409 & 53,409 & 53,409 \\
\hline Pseudo-R ${ }^{2}$ & 0.002 & 0.020 & 0.024 & 0.006 & 0.023 & 0.027 \\
\hline
\end{tabular}




\section{Table IX: Firm Behavior on Conference Calls (Global)}

This table examines the likelihood of an analyst having an opportunity to ask a question in a conference call in the international setting. Our sample includes conference calls in four foreign countries: Canada (columns 1-2), UK (columns 3-4), France (columns 5-6), and Japan (columns 7-8). The dependent variable in all columns is an indicator that takes the value of one if the analyst asks a question in the conference call and zero otherwise. Columns 1, 3, 5, and 7 conduct a panel OLS regression, where the main independent variable is the average recommendation level of the analyst in the year prior to the conference call $(R E C D)$. Columns 2, 4, 6, and 8 conduct a pooled logit regression, where the main independent variable is the prioryear average recommendation level of the analyst relative to the firm's consensus recommendation $\left(R E C D^{a d j}\right)$. Other control variables include: the number of years the analyst has covered the firm $(L E N G T H)$, the number of years the analyst has been in the IBES database (CAREER), the number of stocks covered by the analyst, the number of stocks covered by the broker (a measure of broker size). Columns 1, 3, 5, and 7 also include firm*quarter fixed effects. Standard errors, clustered at both the firm and quarter level, are shown in parenthesis. ${ }^{*}, * *, * * *$ denote significance at the $10 \%, 5 \%$, and $1 \%$ level, respectively.

\begin{tabular}{|c|c|c|c|c|c|c|c|c|}
\hline & $I N_{i, j, t}$ & $I N_{i, j, t}$ & $I N_{i, j, t}$ & $I N_{i, j, t}$ & $I N_{i, j, t}$ & $I N_{i, j, t}$ & $I N_{i, j, t}$ & $I N_{i, j, t}$ \\
\hline & {$[1]$} & {$[2]$} & {$[3]$} & {$[4]$} & {$[5]$} & {$[6]$} & {$[7]$} & {$[8]$} \\
\hline & \multicolumn{2}{|c|}{ Canada } & \multicolumn{2}{|c|}{ UK } & \multicolumn{2}{|c|}{ France } & \multicolumn{2}{|c|}{ Japan } \\
\hline$R E C D_{i, j, t}$ & $\begin{array}{c}0.023^{* * *} \\
(0.004)\end{array}$ & & $\begin{array}{c}0.017^{* * *} \\
(0.003)\end{array}$ & & $\begin{array}{c}0.011^{* * *} \\
(0.004)\end{array}$ & & $\begin{array}{c}0.024^{* *} \\
(0.012)\end{array}$ & \\
\hline$R E C D_{i, j, t}^{a d j}$ & & $\begin{array}{c}0.102^{* * *} \\
(0.021)\end{array}$ & & $\begin{array}{c}0.115^{* * *} \\
(0.022)\end{array}$ & & $\begin{array}{c}0.097^{* * *} \\
(0.029)\end{array}$ & & $\begin{array}{c}0.160^{* *} \\
(0.079)\end{array}$ \\
\hline $\operatorname{LENGTH}_{j, t}$ & $\begin{array}{l}-0.015 \\
(0.012)\end{array}$ & $\begin{array}{c}-0.108^{*} \\
(0.063)\end{array}$ & $\begin{array}{c}0.027^{* * *} \\
(0.007)\end{array}$ & $\begin{array}{c}0.120^{* * *} \\
(0.036)\end{array}$ & $\begin{array}{c}0.009 \\
(0.007)\end{array}$ & $\begin{array}{c}0.069 \\
(0.050)\end{array}$ & $\begin{array}{c}0.067^{* * *} \\
(0.013)\end{array}$ & $\begin{array}{c}0.485^{* * *} \\
(0.095)\end{array}$ \\
\hline $\operatorname{CAREER}_{j, t}$ & $\begin{array}{l}-0.007 \\
(0.010)\end{array}$ & $\begin{array}{c}0.007 \\
(0.046)\end{array}$ & $\begin{array}{c}0.021^{* * *} \\
(0.005)\end{array}$ & $\begin{array}{c}0.146^{* * *} \\
(0.036)\end{array}$ & $\begin{array}{c}0.030^{* * *} \\
(0.009)\end{array}$ & $\begin{array}{c}0.241^{* * *} \\
(0.075)\end{array}$ & $\begin{array}{c}0.054^{* * *} \\
(0.020)\end{array}$ & $\begin{array}{c}0.399 * * \\
(0.172)\end{array}$ \\
\hline$\# S T O C K_{j, t}^{\text {analyst }}$ & $\begin{array}{c}0.033^{* * *} \\
(0.008)\end{array}$ & $\begin{array}{c}0.046 \\
(0.039)\end{array}$ & $\begin{array}{c}-0.017^{* * *} \\
(0.006)\end{array}$ & $\begin{array}{l}-0.038 \\
(0.038)\end{array}$ & $\begin{array}{l}-0.008 \\
(0.007)\end{array}$ & $\begin{array}{l}-0.011 \\
(0.047)\end{array}$ & $\begin{array}{c}-0.053^{* * *} \\
(0.010)\end{array}$ & $\begin{array}{c}-0.374^{* * *} \\
(0.125)\end{array}$ \\
\hline$\#$ \#TOCK $K_{j, t}^{\text {broker }}$ & $\begin{array}{c}0.027^{* * *} \\
(0.006)\end{array}$ & $\begin{array}{c}0.079^{* * *} \\
(0.024)\end{array}$ & $\begin{array}{c}0.057^{* * *} \\
(0.004)\end{array}$ & $\begin{array}{c}0.393^{* * *} \\
(0.030)\end{array}$ & $\begin{array}{c}0.059^{* * *} \\
(0.007)\end{array}$ & $\begin{array}{c}0.542^{* * *} \\
(0.056)\end{array}$ & $\begin{array}{c}0.011 \\
(0.014)\end{array}$ & $\begin{array}{c}0.124 \\
(0.104)\end{array}$ \\
\hline No Obs. & 49,159 & 49,159 & 39,934 & 39,934 & 25,302 & 25,302 & 9,497 & 9,497 \\
\hline Adj-/Pseudo R ${ }^{2}$ & 0.120 & 0.003 & 0.053 & 0.031 & 0.062 & 0.047 & 0.080 & 0.061 \\
\hline
\end{tabular}




\section{Table X: Future Announcement Day Returns (Global)}

This table reports forecasting regressions of earnings announcement day returns on lagged differences in average recommendations between analysts that ask questions in the conference call and those that do not in the international setting. Our sample includes conference calls in four foreign countries: Canada (column 1), UK (column 2), France (column 3), and Japan (column 4). In column 5, we pool all observations from the four countries together. The dependent variable in each column is the cumulative abnormal return in the five day window around the next earnings announcement $(C A R$, in \%). The main independent variable is a dummy variable equal to one if the prior-year average lagged recommendation level of in-analysts is greater than that of out-analysts $(R E C D(I N)>\operatorname{RECD}(O U T))$, and zero otherwise. We also include in the regression lagged analyst forecast dispersion, analyst recommendation dispersion, and the number of analysts covering the firm. In each column, we conduct a Fama-MacBeth regression with Newey-West adjusted standard errors of four lags. $*, * *, * * *$ denote significance at the $10 \%, 5 \%$, and $1 \%$ level, respectively.

\begin{tabular}{lccccc}
\hline & CAR $_{i, t+1}$ & CAR $_{i, t+1}$ & CAR $_{i, t+1}$ & \multicolumn{1}{c}{ CAR $_{i, t+1}$} & CAR $_{i, t+1}$ \\
\hline & {$[1]$} & {$[2]$} & {$[3]$} & {$[4]$} & {$[5]$} \\
\hline RECD $(I N)_{i, t} \geq$ & Canada & UK & France & Japan & All \\
RECD $(\text { OUT })_{i, t}$ & $-0.594^{* * *}$ & $-0.862^{* * *}$ & $-0.791^{* *}$ & $-0.994^{*}$ & $-0.530^{* * *}$ \\
& $(0.188)$ & $(0.284)$ & $(0.387)$ & $(0.571)$ & $(0.165)$ \\
FCSTDISP $_{i, t}$ & & & & & \\
& -0.903 & 0.991 & 5.966 & 0.954 & 0.264 \\
RECDDISP $_{i, t}$ & $(0.615)$ & $(0.672)$ & $(5.373)$ & $(1.249)$ & $(0.504)$ \\
& 0.000 & 0.012 & -0.029 & $0.094^{* *}$ & $0.011^{* *}$ \\
\#ANALYST & $(0.006)$ & $(0.008)$ & $(0.020)$ & $(0.039)$ & $(0.005)$ \\
& -0.028 & $-0.039^{*}$ & -0.093 & -0.107 & $-0.071^{* *}$ \\
& $(0.041)$ & $(0.022)$ & $(0.116)$ & $(0.359)$ & $(0.034)$ \\
No. Qtrs. & & & & & \\
Adj-R & 44 & 28 & 34 & 27 & 44 \\
\hline
\end{tabular}




\section{Table XI: Order of Questions}

This table examines the order of the questions asked. The dependent variable in all columns is the order of analysts asking questions (e.g., the first questioner would have a value of one). The main independent variables include: the average recommendation level of the analyst in the year prior to the conference call $(R E C D)$, whether the analyst is an all-star analyst $(A L L S T A R)$, whether the analyst is affiliated with a broker that underwrites for the firm in question (AFFILIATE), and the number of All-Star analysts employed by the broker (PRESTIGE), which is a common measure of broker prestige. We also interact the analyst's recommendation with these status variables. Other analyst-level controls include: the number of years the analyst has covered the firm (LENGTH), the number of years the analyst has been in the IBES database (CAREER), the number of stocks covered by the analyst, the number of stocks covered by the broker. In each column, we conduct a pooled OLS with firm*quarter fixed effects. Standard errors, clustered at both the firm and quarter level, are shown in parenthesis. * , **, *** denote significance at the $10 \%, 5 \%$, and $1 \%$ level, respectively.

\begin{tabular}{|c|c|c|c|c|c|c|}
\hline & $O R D E R_{i, j, t}$ & $O R D E R_{i, j, t}$ & $O R D E R_{i, j, t}$ & $O R D E R_{i, j, t}$ & $O R D E R_{i, j, t}$ & $O R D E R_{i, j, t}$ \\
\hline & [1] & {$[2]$} & {$[3]$} & {$[4]$} & {$[5]$} & {$[6]$} \\
\hline$R E C D_{i, j, t}$ & $\begin{array}{c}-0.167^{* * *} \\
(0.020)\end{array}$ & $\begin{array}{c}-0.193^{* * *} \\
(0.020)\end{array}$ & $\begin{array}{c}-0.209^{* * *} \\
(0.020)\end{array}$ & $\begin{array}{c}-0.219^{* * *} \\
(0.020)\end{array}$ & $\begin{array}{c}-0.172^{* * *} \\
(0.021)\end{array}$ & $\begin{array}{c}-0.185^{* * *} \\
(0.021)\end{array}$ \\
\hline$A L L S T A R_{j, t}$ & & & $\begin{array}{c}-0.706^{* * *} \\
(0.040)\end{array}$ & $\begin{array}{c}-0.630^{* * *} \\
(0.040)\end{array}$ & $\begin{array}{c}-0.334^{* * *} \\
(0.115)\end{array}$ & $\begin{array}{c}-0.281^{* * *} \\
(0.118)\end{array}$ \\
\hline$A L L S T A R_{j, t} * R E C D$ & & & & & $\begin{array}{c}-0.103^{* * *} \\
(0.033)\end{array}$ & $\begin{array}{c}-0.097^{* * *} \\
(0.034)\end{array}$ \\
\hline AFFILIATE $_{j, t}$ & & & $\begin{array}{c}-0.365^{* * *} \\
(0.065)\end{array}$ & $\begin{array}{c}-0.307^{* * *} \\
(0.064)\end{array}$ & $\begin{array}{c}0.290 \\
(0.301)\end{array}$ & $\begin{array}{c}0.361 \\
(0.298)\end{array}$ \\
\hline AFFILIATE $_{j, t} *$ RECD & & & & & $\begin{array}{c}-0.169^{* *} \\
(0.073)\end{array}$ & $\begin{array}{c}-0.172^{* *} \\
(0.072)\end{array}$ \\
\hline PRESTIGE $E_{j, t}$ & & & $\begin{array}{c}-0.225^{* * *} \\
(0.043)\end{array}$ & $\begin{array}{c}-0.150^{* * *} \\
(0.041)\end{array}$ & $\begin{array}{c}0.154 \\
(0.161)\end{array}$ & $\begin{array}{c}0.175 \\
(0.160)\end{array}$ \\
\hline$P R E S T I G E_{j, t} * R E C D$ & & & & & $\begin{array}{c}-0.106^{* *} \\
(0.045)\end{array}$ & $\begin{array}{c}-0.091^{* *} \\
(0.045)\end{array}$ \\
\hline Other Controls & No & Yes & No & Yes & No & Yes \\
\hline No. Obs. & 313,179 & 313,179 & 313,179 & 313,179 & 313,179 & 313,179 \\
\hline $\operatorname{Adj}-R^{2}$ & 0.142 & 0.147 & 0.150 & 0.152 & 0.150 & 0.152 \\
\hline
\end{tabular}




\section{Figure 1: Sealed Air Corporation Q1 2007 Conference Call}

This figure gives excerpts from Sealed Air Corporation's Q1 2007 earnings conference call, which occurred on April 25, 2007.

Panel A: Joking and complimenting cash usage

Operator

Yes, we'll be going back to George Staphos with Banc Of America Securities.

Bill Hickey - Sealed Air - President, CEO

George, we missed you.

George Staphos - Banc Of America Securities - Analyst

Oh, well, I had another conference call, as well. I apologize. Their result weren't nearly as good as yours, Bill, I'll let you know that.

Bill Hickey - Sealed Air - President, CEO

Thank you, I appreciate that. I appreciate that you went to where you had to go. Somewhere you'd like to go. [laughter]

George Staphos - Banc OfAmerica Securities - Analyst

Sometimes order isn't priorities..

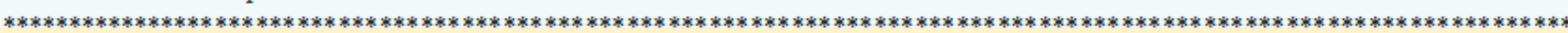

Edings Thibault - Morgan Stanley - Analyst

Thank you very much, Bill. I was hoping we could return to this issue of cash usage, because you guys are starting to turn out some pretty good cash flow here...

Bill Hickey - Sealed Air - President, CEO

Yes, well it's an interesting challenge....we haven't sort of made any conclusions as to what to do with the extra cash we have right now. But I hope you can count on us. I'm sure you can count on us to spend it wisely.

Panel B: Familiarity and analyst pointing out successful strategy (with no real question)

\section{Operator}

Next we'll hear from Tim Burns with Cranial Capital.

Tim Burns - Cranial Capital - Analyst

Good morning from London, Bill, how are you?

Bill Hickey - Sealed Air - President, CEO

Tim, haven't heard from you in ages.

Tim Burns - Cranial Capital - Analyst

I'm ready to jump that river any time...but even beyond that is the question of, your best plants in the right areas to be able to accommodate that and growth, I guess.

Bill Hickey - Sealed Air - President, CEO

Yes. Tim, we're in that process...So we're in the right place with the right product at the right cost at the right time.

You've actually hit the objective of our manufacturing strategy, which we've been talking about, Tim, so thank you for reminding everyone.

Tim Burns - Cranial Capital - Analyst

Sure. Thanks. 
Panel C: More complimenting

Operator
We'll now take a follow-up question from Ross Galardi with Merrill Lynch.

Ross Galardi - Merrill Lynch - Analyst

Thank you. I was just wondering, Bill, if you could elaborate on the strong price mix that you had in the U.S. this quarter. It actually looks like it was better than international. What's driving that?

Bill Hickey - Sealed Air - President, CEO

Primarily focus on profitability. We -- I mean, market share has never been a Sealed Air focus. We essentially focus on selling the right mix of products at profitable -- that are profitable to us and cost savings to our customers. And that focus really came through in the first quarter. 


\section{Figure 2: Histogram of the Distribution of Casting Episode Length}

This figure shows the number of quarters that each casting episode lasts in our sample -i.e., situations where a firm calls on ex-ante more favorable analysts in the earnings call $(\operatorname{RECD}(\operatorname{IN})>\operatorname{RECD}(O U T))$. So, for instance, about $38 \%$ of the cases of casting by firms are for a single quarter.

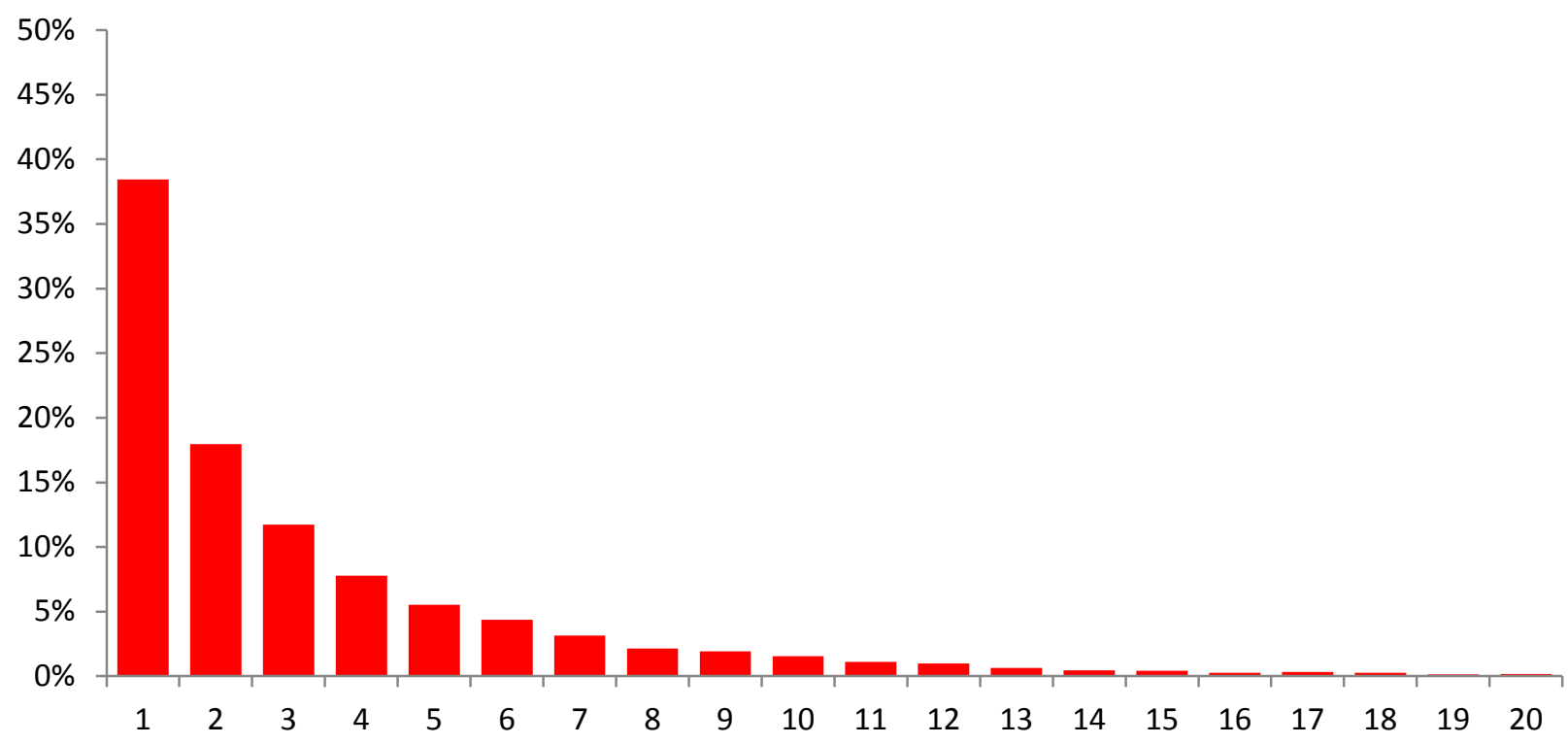




\section{Playing Favorites: \\ How Firms Prevent the Revelation of Bad News}

\section{ONLINE APPENDIX}

(The table numbers in the parentheses indicate which table in the main text each appendix table is associated with, if any.) 
Table A1: Additional Summary Statistics (Table I)

This table reports additional summary statistics of our sample. Panel A corresponds to the US sample, and Panel B corresponds to the pooled international sample (which includes Canada, UK, France, and Japan). Firm-level variables include: MKTCAP is the market capitalization of the firm (in \$billion); BM is the book-to-market ratio; RET12 is the cumulative return over the past 12 months; TURNOVER 12 is the average monthly turnover over the past 12 months; IDIOVOL is the daily idiosyncratic volatility with respect to the Carhart four-factor mode over the past year; INSTOWN is the fraction of shares outstanding owned by institutional investors (as reported in $13 \mathrm{~F}$ filings); ACCRUALS is the discretionary accruals based on the Jones (1991) model; FCDISP is the standard deviation of the most recent earnings forecasts across all analysts covering the firm; RECDDISP is the standard deviation of the most recent stock recommendations level by all analysts; $S U E 0$ is a dummy that equals one if the firm has a zero or one cent earnings surprise and zero otherwise; $S E O$ is an indicator that equals one if the firm has at least one seasoned equity offering in a quarter and zero otherwise; INSIDER is an indicator that equals one if the firm has positive net insider selling in a quarter and zero otherwise; EXERCISE is an indicator that equals one if top executives exercise their stock options in a quarter and zero otherwise; and GRANT is an indicator that equals one if top executives receive option grants in a quarter and zero otherwise. Analyst-level variables include: $L E N G T H$ is the number of years the analyst has covered the firm; $C A R E E R$ is the number of years the analyst has been in the IBES database; \#STOCK_ANALYST is the number of stocks covered by the analyst; and \#STOCK_BROKER is the number of stocks covered by the broker (a measure of broker size); $A L L S T A R$ is an indicator that equals one if the analyst is an all-star and zero otherwise; AFFILIATE is an indicator is the analyst is affiliated with a broker that underwrites for the firm in question and zero otherwise; FCERROR is the earnings forecast error in the following quarter (defined as the absolute difference between the analyst's most recent earnings forecast and the actual reported earnings). We report in the table below the mean, standard deviation, $1^{\text {st }}, 25^{\text {th }}, 50^{\text {th }}, 75^{\text {th }}$, and $99^{\text {th }}$ percentiles of the distribution of each variable.

\begin{tabular}{lccccccc}
\hline \multicolumn{7}{c}{ Panel A: US Firms } \\
\hline Firm Characteristics & Mean & Std Dev & P1 & Q1 & Median & Q3 & P99 \\
\hline M KTCAP $(\$ B)$ & 7.61 & 24.22 & 0.05 & 0.56 & 1.56 & 4.81 & 120.54 \\
BM & 0.61 & 0.57 & 0.05 & 0.29 & 0.48 & 0.76 & 2.77 \\
RET12 & 0.13 & 0.49 & -0.72 & -0.15 & 0.10 & 0.34 & 1.76 \\
TURNOVER12 & 2.69 & 2.22 & 0.37 & 1.34 & 2.10 & 3.32 & 10.94 \\
IDIOVOL & 0.02 & 0.01 & 0.01 & 0.01 & 0.02 & 0.03 & 0.07 \\
INSTOWN & 0.70 & 0.20 & 0.14 & 0.59 & 0.75 & 0.86 & 0.99 \\
ACCRUALS & 0.06 & 0.07 & 0.00 & 0.02 & 0.04 & 0.07 & 0.36 \\
FCDISP $(* 100)$ & 0.35 & 3.66 & 0.00 & 0.04 & 0.09 & 0.22 & 4.16 \\
RECDDISP & 0.83 & 0.25 & 0.00 & 0.73 & 0.84 & 0.97 & 1.41 \\
SUE0 & 0.04 & 0.20 & 0.00 & 0.00 & 0.00 & 0.00 & 1.00 \\
SEO & 0.06 & 0.24 & 0 & 0 & 0 & 0 & 1 \\
INSIDER & 0.43 & 0.50 & 0 & 0 & 0 & 1 & 1 \\
EXERCISE & 0.32 & 0.47 & 0 & 0 & 0 & 1 & 1 \\
GRANT & 0.24 & 0.43 & 0 & 0 & 0 & 0 & 1 \\
\hline
\end{tabular}




\begin{tabular}{lccccccc}
\hline \multicolumn{7}{c}{ Panel A: US Firms (Cont'd) } \\
\hline & Mean & Std Dev & P1 & Q1 & Median & Q3 & P99 \\
\hline Analyst Characteristics & & & & & & & \\
\hline LENGTH & 5.74 & 4.68 & 1 & 3 & 4 & 7 & 24 \\
CAREER & 13.30 & 8.11 & 2 & 6 & 12 & 20 & 31 \\
\#STOCK_ANALYST & 17.74 & 8.92 & 1 & 13 & 17 & 22 & 48 \\
\#STOCK_BROKER & 641 & 417 & 14 & 257 & 623 & 977 & 1502 \\
ALLLSTAR & 0.14 & 0.35 & 0 & 0 & 0 & 0 & 1 \\
AFFILIATE & 0.03 & 0.16 & 0 & 0 & 0 & 0 & 1 \\
FCERROR $(* 100)$ & 0.52 & 1.38 & 0.00 & 0.05 & 0.15 & 0.40 & 9.18 \\
\hline
\end{tabular}

Panel B: International Firms

\begin{tabular}{lccccccc}
\hline \multicolumn{7}{c}{ Panel B: International Firms } \\
\hline Firm Characteristics & 0.44 & 2.35 & 0.00 & 0.00 & 0.11 & 0.32 & 6.20 \\
\hline FCDISP $(* 100)$ & 0.86 & 0.24 & 0.00 & 0.70 & 0.85 & 1.01 & 1.46 \\
RECDDISP & & & & & & & \\
\hline Analyst Characteristics & 4.82 & 4.57 & 0 & 2 & 3 & 7 & 20 \\
\hline LENGTH & 11.00 & 7.05 & 0 & 5 & 11 & 17 & 26 \\
CAREER & 11.30 & 6.71 & 1 & 7 & 10 & 14 & 34 \\
\#STOCK_ANALYST & 617 & 695 & 9 & 170 & 314 & 764 & 2878 \\
\#STOCK_BROKER & & & & & & & \\
\hline
\end{tabular}




\section{Table A2: Firm Behavior on Conference Calls (Table II)}

This table examines the likelihood of an analyst having an opportunity to ask a question in the conference call. The dependent variable in all columns is an indicator that takes the value of one if the analyst asks a question in the conference call and zero otherwise. Columns 1 and 2 conduct a panel OLS regression, and columns 3 and 4 conduct a pooled logit regression. The main independent variable in columns 1 and 2 is the average recommendation level of the analyst in the year prior to the conference call $(R E C D)$, and that in columns 3 and 4 is the prior-year average recommendation level of the analyst relative to the consensus recommendation $\left(R E C D^{a d j}\right)$. Analyst level controls include: the number of years the analyst has covered the firm $(L E N G T H)$, the number of years the analyst has been in the IBES database $(C A R E E R)$, the number of stocks covered by the analyst, the number of stocks covered by the broker (a measure of broker size), whether the analyst is an all-star analyst, and whether the analyst is affiliated with a broker that underwrites for the firm in question. We also include in the regression the number of times the analyst has been called on to ask questions in prior earnings conference calls (PASTCALL). We skip the first three years of the sample to compute PASTCALL, which is why we have fewer observations here compared to Table II. Firm level controls include: lagged market capitalization, book to market ratio, past one year stock returns, monthly share turnover in the previous year, daily idiosyncratic volatility in the previous year, number of analysts covering the firm, institutional ownership, and discretionary accruals. Columns 1 and 2 include firm* quarter fixed effects. Standard errors, clustered at both the firm and quarter level, are shown in parenthesis. $*, * *, * * *$ denote significance at the $10 \%, 5 \%$, and $1 \%$ level, respectively.

\begin{tabular}{|c|c|c|c|c|}
\hline & $I N_{i, j, t}$ & $I N_{i, j, t}$ & $I N_{i, j, t}$ & $I N_{i, j, t}$ \\
\hline & [1] & [2] & [3] & [4] \\
\hline \multirow[t]{2}{*}{$R E C D_{i, j, t}$} & $0.036 * * *$ & $0.043^{* * *}$ & & \\
\hline & $(0.002)$ & $(0.002)$ & & \\
\hline \multirow[t]{2}{*}{$R E C D_{i, j, t}^{a d j}$} & & & $0.180^{* * *}$ & $0.216^{* * *}$ \\
\hline & & & (0.008) & (0.009) \\
\hline \multirow[t]{2}{*}{$P A S T C A L L_{i, j, t}$} & $0.027 * * *$ & $0.030^{* * *}$ & $0.111^{* * *}$ & $0.136^{* * *}$ \\
\hline & $(0.001)$ & $(0.001)$ & $(0.006)$ & $(0.006)$ \\
\hline \multirow[t]{2}{*}{ LENGTH $_{j, t}$} & & $-0.128^{* * *}$ & & $-0.737 * * *$ \\
\hline & & $(0.006)$ & & $(0.031)$ \\
\hline \multirow{2}{*}{$C A R E E R_{j, t}$} & & $-0.005^{* *}$ & & 0.002 \\
\hline & & (0.003) & & $(0.012)$ \\
\hline \multirow{2}{*}{$\# S T O C K_{j, t}^{\text {analyst }}$} & & $0.006^{* *}$ & & $0.124^{* * *}$ \\
\hline & & $(0.003)$ & & $(0.016)$ \\
\hline \multirow[t]{2}{*}{$\# S T O C K_{j, t}^{\text {broker }}$} & & $0.032^{* * *}$ & & $0.170^{* * *}$ \\
\hline & & $(0.002)$ & & $(0.010)$ \\
\hline \multirow[t]{2}{*}{$A L L S T A R_{j, t}$} & & $0.043^{* * *}$ & & $0.117 * * *$ \\
\hline & & $(0.006)$ & & $(0.029)$ \\
\hline \multirow[t]{2}{*}{$A F F I L I A T E_{j, t}$} & & $0.032^{* * *}$ & & $0.330^{* * *}$ \\
\hline & & $(0.010)$ & & $(0.036)$ \\
\hline Other Controls & No & No & No & Yes \\
\hline No Obs. & 704,022 & 704,022 & 704,022 & 704,022 \\
\hline Adj/Pseudo R² & 0.141 & 0.171 & 0.126 & 0.093 \\
\hline
\end{tabular}


Table A3: Controlling for Accruals and Dispersion Factors (Table VII)

This table reports monthly returns to a calendar-time portfolio that exploits the return predictability of recommendation differentials between analysts that ask questions in the conference call and those that do not. Specifically, on each day, we rank all firms into five quintiles based on the recommendation differential between in-analysts and out-analysts in the previous quarter. Next, in the five days surrounding the following quarterly earnings announcement, we go long stocks whose $R E C D(I N)-R E C D(O U T)$ in the previous quarter is in the top quintile, and short stocks whose $R E C D(I N)$ $R E C D(O U T)$ in the previous quarter is in the bottom quintile. If on any given day, there are fewer than 5 stocks in either the long or short lag, we hold the 30-day Treasury bill instead (this is the case for less than 10\% of the trading days). We then aggregate these daily returns to the monthly level. Panel A reports the monthly returns to the five quintile portfolios after adjusting for various risk factors; and Panel B reports the risk exposures of these five portfolios. In the full specification, we control for the Carhart four factors (including momentum), the liquidity factor, the accruals factor (CMA, Hirshleifer, Hou, and Teoh, 2012), and the analyst forecast dispersion factor (DISP, i.e., low dispersion portfolio - high dispersion portfolio). T-statistics, with Newey-West adjustments of four lags, are shown in brackets. Estimates significant at the $5 \%$ level are indicated in bold.

\begin{tabular}{ccccccc}
\hline \multicolumn{7}{c}{ Panel A: Portfolio Returns } \\
\hline \multirow{2}{*}{ Quintile } & Excess & $\begin{array}{c}\text { 1-Factor } \\
\text { Returns }\end{array}$ & $\begin{array}{c}\text { 3-Factor } \\
\text { Alpha }\end{array}$ & $\begin{array}{c}\text { 4-Factor } \\
\text { Alpha }\end{array}$ & $\begin{array}{c}\text { Alpha } \\
\text { Alpactor }\end{array}$ & $\begin{array}{c}\text { 7-Factor } \\
\text { Alpha }\end{array}$ \\
\hline \multirow{2}{*}{1} & $1.46 \%$ & $1.08 \%$ & $1.07 \%$ & $1.07 \%$ & $1.03 \%$ & $0.97 \%$ \\
& {$[2.59]$} & {$[1.80]$} & {$[1.88]$} & {$[1.85]$} & {$[1.62]$} & {$[1.39]$} \\
\multirow{2}{*}{2} & $1.26 \%$ & $0.91 \%$ & $0.86 \%$ & $0.90 \%$ & $0.90 \%$ & $0.96 \%$ \\
& {$[2.55]$} & {$[1.65]$} & {$[1.65]$} & {$[1.72]$} & {$[1.54]$} & {$[1.67]$} \\
\multirow{2}{*}{3} & $0.96 \%$ & $0.39 \%$ & $0.35 \%$ & $0.36 \%$ & $0.37 \%$ & $0.41 \%$ \\
& {$[1.87]$} & {$[0.85]$} & {$[0.77]$} & {$[0.80]$} & {$[0.76]$} & {$[0.96]$} \\
\multirow{2}{*}{4} & $0.48 \%$ & $-0.13 \%$ & $-0.19 \%$ & $-0.20 \%$ & $-0.30 \%$ & $-0.21 \%$ \\
& {$[0.75]$} & {$[-0.20]$} & {$[-0.31]$} & {$[-0.32]$} & {$[-0.46]$} & {$[-0.35]$} \\
\multirow{2}{*}{5} & $0.18 \%$ & $-0.43 \%$ & $-0.39 \%$ & $-0.38 \%$ & $-0.44 \%$ & $-0.26 \%$ \\
& {$[0.30]$} & {$[-0.69]$} & {$[-0.65]$} & {$[-0.63]$} & {$[-0.66]$} & {$[-0.43]$} \\
\hline \multirow{2}{*}{$5-1$} & $\mathbf{- 1 . 2 9 \%}$ & $\mathbf{- 1 . 5 3 \%}$ & $\mathbf{- 1 . 4 8 \%}$ & $\mathbf{- 1 . 4 7 \%}$ & $\mathbf{- 1 . 4 9 \%}$ & $\mathbf{- 1 . 2 3 \%}$ \\
& {$[-2.59]$} & {$[-2.86]$} & {$[-2.78]$} & {$[-2.78]$} & {$[-2.64]$} & {$[-2.42]$} \\
\hline
\end{tabular}

\begin{tabular}{|c|c|c|c|c|c|c|c|c|c|}
\hline \multicolumn{10}{|c|}{ Panel B: Factor Loadings } \\
\hline & XRet & Alpha & MKT & SMB & HML & UMD & LIQ & CMA & DISP \\
\hline \multirow[t]{2}{*}{1} & $1.46 \%$ & $0.97 \%$ & 0.154 & 0.701 & 0.563 & 0.042 & 0.080 & 0.284 & 0.003 \\
\hline & {$[2.59]$} & {$[1.39]$} & {$[0.73]$} & {$[3.20]$} & {$[2.24]$} & {$[0.35]$} & {$[0.47]$} & {$[1.60]$} & {$[0.02]$} \\
\hline \multirow[t]{2}{*}{5} & $0.18 \%$ & $-0.26 \%$ & 0.315 & 0.159 & 0.406 & 0.110 & 0.092 & 0.250 & -0.345 \\
\hline & {$[0.30]$} & {$[-0.43]$} & {$[1.36]$} & {$[0.76]$} & {$[1.58]$} & {$[1.09]$} & {$[0.68]$} & {$[1.13]$} & {$[-1.97]$} \\
\hline \multirow[t]{2}{*}{$5-1$} & $-1.29 \%$ & $-1.23 \%$ & 0.161 & -0.542 & -0.157 & 0.068 & 0.012 & -0.034 & -0.348 \\
\hline & {$[-2.59]$} & {$[-2.42]$} & {$[1.30]$} & {$[-2.03]$} & {$[-0.55]$} & {$[0.54]$} & [0.10] & {$[-0.20]$} & {$[-1.95]$} \\
\hline
\end{tabular}




\section{Table A4: Portfolio Returns in Expected Announcement Months (Table VII)}

This table reports monthly returns to a calendar-time portfolio that exploits the return predictability of recommendation differentials between analysts that ask questions in the conference call and those that do not. Importantly, instead of using the actual reporting month, we follow Frazzini and Lamont (2006) to compute expected earnings announcement month, with the assumption that firms report in the same calendar month as four fiscal quarters ago. Specifically, in each month, we rank all firms into five quintiles based on the recommendation differential between in analysts and out analysts in the previous quarter. Next, in the subsequent expected earnings announcement month, we go long stocks whose $R E C D(I N)$ $R E C D(O U T)$ in the previous quarter is in the top quintile, and short stocks whose $R E C D(I N)-R E C D(O U T)$ in the previous quarter is in the bottom quintile. Panel A reports the monthly returns to the five quintile portfolios after adjusting for various risk factors; Panel B reports the risk exposures of these five portfolios. In the full specification, we control for the Carhart four factors (including momentum) and the liquidity factor. T-statistics, with Newey-West adjustments of four lags, are shown in brackets. Estimates significant at the 5\% level are indicated in bold.

\begin{tabular}{cccccc}
\hline \multicolumn{5}{c}{ Panel A: Portfolio Returns } \\
\hline \multirow{2}{*}{ Quintile } & Excess & 1-Factor & 3-Factor & 4-Factor & 5-Factor \\
& Returns & Alpha & Alpha & Alpha & Alpha \\
\hline \multirow{2}{*}{1} & $1.66 \%$ & $0.67 \%$ & $0.60 \%$ & $0.65 \%$ & $0.66 \%$ \\
& {$[2.93]$} & {$[2.46]$} & {$[2.75]$} & {$[3.09]$} & {$[3.15]$} \\
\multirow{2}{*}{2} & $1.16 \%$ & $0.09 \%$ & $0.05 \%$ & $0.08 \%$ & $0.09 \%$ \\
& {$[1.97]$} & {$[0.33]$} & {$[0.18]$} & {$[0.32]$} & {$[0.34]$} \\
\multirow{2}{*}{3} & $1.26 \%$ & $0.24 \%$ & $0.18 \%$ & $0.22 \%$ & $0.24 \%$ \\
& {$[2.27]$} & {$[1.02]$} & {$[0.97]$} & {$[1.19]$} & {$[1.27]$} \\
\multirow{2}{*}{4} & $1.46 \%$ & $0.41 \%$ & $0.35 \%$ & $0.40 \%$ & $0.42 \%$ \\
& {$[2.53]$} & {$[1.61]$} & {$[1.68]$} & {$[1.98]$} & {$[2.03]$} \\
\multirow{2}{*}{5} & $0.99 \%$ & $-0.12 \%$ & $-0.17 \%$ & $-0.11 \%$ & $-0.12 \%$ \\
& {$[1.63]$} & {$[-0.46]$} & {$[-0.75]$} & {$[-0.54]$} & {$[-0.52]$} \\
\hline 5 & $\mathbf{- 0 . 6 7 \%}$ & $\mathbf{- 0 . 7 9 \%}$ & $\mathbf{- 0 . 7 7 \%}$ & $\mathbf{- 0 . 7 6 \%}$ & $\mathbf{- 0 . 7 8 \%}$ \\
& {$[-1.97]$} & {$[-2.50]$} & {$[-2.51]$} & {$[-2.45]$} & {$[-2.45]$} \\
\hline
\end{tabular}

\begin{tabular}{cccccccc}
\hline \multicolumn{7}{c}{ Panel B: Factor Loadings } \\
\hline \multirow{2}{*}{1} & XRet & Alpha & MKT & SMB & HML & UMD & LIQ \\
& $1.66 \%$ & $0.66 \%$ & 0.973 & 0.880 & 0.253 & -0.205 & -0.035 \\
& {$[2.93]$} & {$[3.15]$} & {$[16.62]$} & {$[7.69]$} & {$[2.31]$} & {$[-3.65]$} & {$[-0.81]$} \\
5 & $0.99 \%$ & $-0.12 \%$ & 1.202 & 0.721 & -0.001 & -0.241 & 0.007 \\
& {$[1.63]$} & {$[-0.52]$} & {$[21.25]$} & {$[6.23]$} & {$[-0.01]$} & {$[-4.12]$} & {$[0.10]$} \\
\hline $5-1$ & $\mathbf{- 0 . 6 7 \%}$ & $\mathbf{- 0 . 7 8 \%}$ & $\mathbf{0 . 2 2 8}$ & -0.159 & -0.254 & -0.037 & 0.042 \\
& {$[-1.97]$} & {$[-2.45]$} & {$[2.52]$} & {$[-0.92]$} & {$[-1.59]$} & {$[-0.42]$} & {$[0.50]$} \\
\hline
\end{tabular}


Table A5: Positive vs. Negative Words

This table examines the tone of analysts' questions in conference calls. The dependent variable in columns 1 and 2 is the number of positive words minus the number of negative words in a question scaled by the total number of words in the question $\left(\right.$ POSRATIO $=\frac{\# \text { poswords-\#negwords }}{\# \text { words }}$, where positive and negative words are defined as in Loughran and McDonald (2011). The dependent variable in columns 3 and 4 is the difference between the log of the number of positive words and that of negative words in the question $\left(P O S T O N E^{Q}=\log (\# p o s w o r d s+1)-\log (\# n e g\right.$ words +1$\left.)\right)$. The main independent variable is the average recommendation level of the analyst in the year prior to the conference call. Other control variables include: the analyst's PLACE in the conference call (e.g., second in line to ask a question), the number of years the analyst has covered the firm (LENGTH), the number of years the analyst has been in the IBES database $(C A R E E R)$, the number of stocks covered by the analyst, the number of stocks covered by the broker (as a measure of broker size), whether the analyst is an all-star analyst, and whether the analyst is affiliated with a broker that underwrites for the firm in question. All specifications include firm* quarter fixed effects. Standard errors, clustered at both the firm and quarter level, are shown in parenthesis. *, **, *** denote significance at the 10\%, 5\%, and 1\% level, respectively.

\begin{tabular}{|c|c|c|c|c|}
\hline & POSRATIO $Q$ & POSRATIO $Q$ & POSTONE $E_{i, j, t}^{Q}$ & POSTONE $E_{i, j, t}^{Q}$ \\
\hline & [1] & [2] & [3] & {$[4]$} \\
\hline \multirow{2}{*}{$R E C D_{i, j, t}$} & $0.031 * * *$ & $0.034 * * *$ & $0.014 * * *$ & $0.014 * * *$ \\
\hline & $(0.011)$ & $(0.011)$ & $(0.005)$ & $(0.004)$ \\
\hline \multirow{2}{*}{$P L A C E_{i, j, t}$} & $-0.011 * * *$ & $-0.011 * * *$ & $-0.003^{* * *}$ & $-0.003^{* * *}$ \\
\hline & $(0.002)$ & $(0.002)$ & $(0.001)$ & $(0.001)$ \\
\hline \multirow{2}{*}{$\operatorname{LENGTH}_{j, t}$} & & $-0.032^{* * *}$ & & $-0.011 * *$ \\
\hline & & $(0.009)$ & & $(0.005)$ \\
\hline \multirow[t]{2}{*}{ CAREER $_{j, t}$} & & $-0.032^{* * *}$ & & $-0.017 * * *$ \\
\hline & & (0.011) & & $(0.005)$ \\
\hline \multirow{2}{*}{$\# S T O C K_{j, t}^{\text {analyst }}$} & & $0.049 * * *$ & & $0.028^{* * *}$ \\
\hline & & $(0.019)$ & & $(0.008)$ \\
\hline \multirow[t]{2}{*}{$\# S T O C K_{j, t}^{\text {broker }}$} & & 0.005 & & -0.000 \\
\hline & & $(0.008)$ & & $(0.003)$ \\
\hline \multirow[t]{2}{*}{$A_{L L S T A R_{j, t}}$} & & -0.034 & & -0.016 \\
\hline & & $(0.022)$ & & $(0.010)$ \\
\hline \multirow[t]{2}{*}{ AFFILIATE $E_{j, t}$} & & 0.061 & & 0.022 \\
\hline & & $(0.041)$ & & $(0.017)$ \\
\hline No Obs. & 311,924 & 311,924 & 311,924 & 311,924 \\
\hline Adj- $R^{2}$ & 0.051 & 0.051 & 0.099 & 0.099 \\
\hline
\end{tabular}




\section{Table A6: Contemporaneous Investor Response}

This table conducts Fama-MacBeth regressions of earnings announcement day returns on the contemporaneous difference in average recommendations between analysts that ask questions in the conference call and those that do not. The dependent variable is the cumulative abnormal return in days 0 to 2 of the quarterly earnings announcement (in \%). The main independent variable in columns $1-3$ is the difference in average prior-year recommendations between in-analysts and out-analysts measured in the same quarter $(R E C D(I N)-R E C D(O U T))$, and that in columns 4-6 is a dummy that equals one if this recommendation differential is greater than zero, and zero otherwise. Other control variables include: the standardized unexpected earnings, and its squared term, analyst forecast dispersion and recommendation dispersion, institutional ownership, number of analysts covering the firm, market capitalization, book to market ratio, past one year stock returns, monthly share turnover in the past year, daily idiosyncratic volatility in the past year, and discretionary accruals. Standard errors, with Newey-West adjustments of four lags, are shown in parenthesis. *, **, *** denote significance at the $10 \%, 5 \%$, and $1 \%$ level, respectively.

\begin{tabular}{|c|c|c|c|c|c|c|}
\hline \multicolumn{7}{|c|}{ Dependent Variable $=C A R_{i, t}$} \\
\hline & [1] & [2] & [3] & [4] & [5] & [6] \\
\hline $\operatorname{RECD}(I N)_{i, t}-$ & $0.156^{* *}$ & $0.153^{* *}$ & $0.148^{* *}$ & & & \\
\hline$R E C D(O U T)_{i, t}$ & $(0.073)$ & $(0.069)$ & $(0.074)$ & & & \\
\hline $\operatorname{RECD}(I N)_{i, t}>$ & & & & $0.165^{* * *}$ & $0.163^{* * *}$ & $0.174 * * *$ \\
\hline$R E C D(O U T)_{i, t}$ & & & & $(0.042)$ & $(0.041)$ & $(0.046)$ \\
\hline \multirow[t]{2}{*}{$S U E_{i, t}$} & $2.893 * * *$ & $2.910^{* * *}$ & $2.917 * * *$ & $2.895^{* * *}$ & $2.912 * * *$ & $2.917 * * *$ \\
\hline & $(0.138)$ & $(0.140)$ & $(0.143)$ & $(0.138)$ & $(0.140)$ & $(0.143)$ \\
\hline \multirow[t]{2}{*}{$S U E_{i, t}^{2}$} & $0.116^{* * *}$ & $0.130^{* * *}$ & $0.134 * * *$ & $0.116^{* * *}$ & $0.130^{* * *}$ & $0.134 * * *$ \\
\hline & $(0.028)$ & $(0.024)$ & $(0.023)$ & $(0.028)$ & $(0.024)$ & $(0.023)$ \\
\hline \multirow[t]{2}{*}{ FCSTDISP $_{i, t}$} & & $-0.353^{* * *}$ & $-0.237 * *$ & & $-0.350 * * *$ & $-0.234 * *$ \\
\hline & & $(0.113)$ & $(0.106)$ & & $(0.112)$ & $(0.106)$ \\
\hline \multirow[t]{2}{*}{$R E C D D I S P_{i, t}$} & & $-0.205^{* *}$ & -0.161 & & $-0.209 * *$ & -0.166 \\
\hline & & $(0.086)$ & $(0.098)$ & & $(0.089)$ & $(0.102)$ \\
\hline \multirow[t]{2}{*}{ INSTOWN $_{i, t}$} & & $0.636^{* * *}$ & $0.668^{* * *}$ & & $0.623^{* * *}$ & $0.651^{* * *}$ \\
\hline & & $(0.166)$ & $(0.197)$ & & $(0.163)$ & $(0.193)$ \\
\hline \multirow[t]{2}{*}{$\# A N A L Y S T_{i, t}$} & & -0.062 & 0.082 & & -0.070 & 0.075 \\
\hline & & $(0.090)$ & $(0.106)$ & & $(0.092)$ & $(0.107)$ \\
\hline Other Controls & No & No & Yes & No & No & Yes \\
\hline F-M \# Qtrs & 49 & 49 & 49 & 49 & 49 & 49 \\
\hline Adj- $\mathrm{R}^{2}$ & 0.075 & 0.081 & 0.095 & 0.075 & 0.081 & 0.095 \\
\hline
\end{tabular}




\section{Table A7: Analyst Earnings Forecast Errors}

This table examines the earnings forecast accuracy of analysts that ask questions in the conference call vs. those that do not. The dependent variable in all columns is the earnings forecast error (in \%) in the following quarter (defined as the absolute difference between the analyst's most recent earnings forecast and the actual reported earnings). The main independent variable is the $I N$ dummy that takes the value of one if the analyst asks a question in the conference call in the current quarter and zero otherwise. Analyst level controls include: the number of years the analyst has covered the firm (LENGTH), the number of years the analyst has been in the IBES database (CAREER), the number of stocks covered by the analyst, the number of stocks covered by the broker (a measure of broker size), whether the analyst is an all-star analyst, and whether the analyst is affiliated with a broker that underwrites for the firm in question. Firm level controls include: lagged market capitalization, book to market ratio, past one year stock returns, monthly share turnover over the past year, daily idiosyncratic volatility over the past year, number of analysts covering the firm, institutional ownership, and discretionary accruals. Columns 1 and 2 include firm*quarter fixed effects and examine the relative accuracy of inanalysts and out-analysts covering the same firm. Columns 3 and 4 include analyst*quarter fixed effects and examine the relative accuracy of in-stocks (for which the analyst asks a question) and out-stocks (for which the analyst does not ask a question) covered by the same analyst. Finally, Columns 5 and 6 include firm*quarter fixed effects and examine the relative accuracy of in-analysts (of at least one conference call) and out-analysts covering the same firm where neither of the two analysts is in the conference call in question. Standard errors, clustered at both the firm and quarter level, are shown in parenthesis. *, **, *** denote significance at the $10 \%, 5 \%$, and $1 \%$ level, respectively.

\begin{tabular}{|c|c|c|c|c|c|c|}
\hline & $F C E_{i, j, t+1}$ & $F C E_{i, j, t+1}$ & $F C E_{i, j, t+1}$ & $F C E_{i, j, t+1}$ & $F C E_{i, j, t+1}$ & $F C E_{i, j, t+1}$ \\
\hline & [1] & [2] & [3] & [4] & [5] & [6] \\
\hline$I N_{i, j, t}$ & $\begin{array}{c}-0.010^{* * *} \\
(0.002)\end{array}$ & $\begin{array}{c}-0.010^{* * *} \\
(0.002)\end{array}$ & $\begin{array}{c}-0.065^{* * *} \\
(0.013)\end{array}$ & $\begin{array}{c}-0.028^{* * *} \\
(0.010)\end{array}$ & $\begin{array}{c}-0.005^{* *} \\
(0.002)\end{array}$ & $\begin{array}{l}-0.003 \\
(0.002)\end{array}$ \\
\hline$L E N G T H_{j, t}$ & & $\begin{array}{l}-0.001 \\
(0.001)\end{array}$ & & & & $\begin{array}{l}-0.001 \\
(0.001)\end{array}$ \\
\hline $\operatorname{CAREER}_{j, t}$ & & $\begin{array}{l}-0.001 \\
(0.001)\end{array}$ & & & & $\begin{array}{c}0.000 \\
(0.002)\end{array}$ \\
\hline$\#$ \#TOCK $K_{j, t}^{\text {analyst }}$ & & $\begin{array}{c}0.001 \\
(0.002)\end{array}$ & & & & $\begin{array}{c}0.002 \\
(0.002)\end{array}$ \\
\hline$\#$ \#TOCK $K_{j, t}^{\text {broker }}$ & & $\begin{array}{c}-0.002^{* *} \\
(0.001)\end{array}$ & & & & $\begin{array}{c}-0.003^{* *} \\
(0.001)\end{array}$ \\
\hline$A L L S T A R_{j, t}$ & & $\begin{array}{l}0.007 * \\
(0.004)\end{array}$ & & & & $\begin{array}{c}0.008 \\
(0.006)\end{array}$ \\
\hline AFFILIATE $_{j, t}$ & & $\begin{array}{c}0.006 \\
(0.004)\end{array}$ & & & & $\begin{array}{c}0.005 \\
(0.005)\end{array}$ \\
\hline Other Controls & No & No & No & Yes & No & No \\
\hline No Obs. & 527,827 & 527,827 & 514,614 & 514,614 & 355,337 & 355,337 \\
\hline Adj-R ${ }^{2}$ & 0.850 & 0.850 & 0.138 & 0.214 & 0.849 & 0.849 \\
\hline
\end{tabular}




\section{Table A8: Drop in Analyst Coverage}

This table reports regressions of subsequent changes in analyst coverage on lagged recommendation differentials between analysts that ask questions in the conference call and those that do not. The dependent variable in all columns is the number of analysts covering the firm in the following year (we also control for analyst coverage in the previous year). The main independent variable, CASTING, is defined as the average recommendation differential between in-analysts and outanalysts $(R E C D(I N)-R E C D(O U T))$ in the previous four quarters in columns 1 and 2 , and it is equal to the fraction of quarters in which $R E C D(I N)$ is greater than $R E C D(O U T)$ in the previous four quarters in columns 3 and 4 . Other control variables include: analyst forecast dispersion, analyst recommendation dispersion, institutional ownership, market capitalization, book to market ratio, past one year stock returns, monthly share turnover in the past year, daily idiosyncratic volatility in the past year, and discretionary accruals. In each column, we conduct a pooled OLS regression. Standard errors, clustered at both the firm and quarter level, are reported in parenthesis. *, **, *** denote significance at the 10\%, 5\%, and $1 \%$ level, respectively.

\begin{tabular}{|c|c|c|c|c|}
\hline & $\# A N L S T_{i, t+1}$ & $\# A N L S T_{i, t+1}$ & $\# A N L S T_{i, t+1}$ & $\# A N L S T_{i, t+1}$ \\
\hline & [1] & [2] & [3] & [4] \\
\hline \multirow{2}{*}{ CASTING $_{i, t}$} & $-0.512^{* *}$ & $-0.391 * *$ & $-0.367 *$ & $-0.458^{* *}$ \\
\hline & $(0.244)$ & $(0.196)$ & $(0.214)$ & $(0.212)$ \\
\hline \multirow[t]{2}{*}{$\# A N L S T_{i, t}$} & $0.667^{* * *}$ & $0.639 * * *$ & $0.669^{* * *}$ & $0.640^{* * *}$ \\
\hline & $(0.073)$ & $(0.066)$ & $(0.073)$ & $(0.066)$ \\
\hline \multirow[t]{2}{*}{$F C S T D I S P_{i, t}$} & & -3.109 & & -3.106 \\
\hline & & (1.928) & & (1.928) \\
\hline \multirow[t]{2}{*}{$R E C D D I S P_{i, t}$} & & $1.653^{* * *}$ & & $1.642^{* * *}$ \\
\hline & & $(0.387)$ & & $(0.387)$ \\
\hline \multirow[t]{2}{*}{$\operatorname{INSTOWN}_{i, t}$} & & $0.975^{* *}$ & & $0.978^{* *}$ \\
\hline & & $(0.398)$ & & $(0.399)$ \\
\hline \multirow[t]{2}{*}{$M K T C A P_{i, t}$} & & $1.580^{* * *}$ & & $1.583^{* * *}$ \\
\hline & & $(0.136)$ & & $(0.136)$ \\
\hline \multirow[t]{2}{*}{$B M_{i, t}$} & & $-1.920^{* * *}$ & & $-1.924 * * *$ \\
\hline & & $(0.356)$ & & $(0.357)$ \\
\hline \multirow[t]{2}{*}{$R E T 12_{i, t}$} & & -0.358 & & -0.359 \\
\hline & & $(0.757)$ & & $(0.757)$ \\
\hline \multirow[t]{2}{*}{ TURNOVER $R_{i, t}$} & & $0.628^{* * *}$ & & $0.629 * * *$ \\
\hline & & $(0.078)$ & & $(0.079)$ \\
\hline \multirow[t]{2}{*}{$\operatorname{IDIOVOL}_{i, t}$} & & $1.013^{* * *}$ & & $1.013^{* * *}$ \\
\hline & & $(0.232)$ & & $(0.232)$ \\
\hline \multirow[t]{2}{*}{$\operatorname{DISCACCRUAL}_{i, t}$} & & $-5.607 * * *$ & & $-5.585^{* * *}$ \\
\hline & & $(1.513)$ & & $(1.512)$ \\
\hline Other Controls & Yes & Yes & Yes & Yes \\
\hline No Obs. & 36,946 & 36,946 & 36,946 & 36,946 \\
\hline $\operatorname{Adj}-R^{2}$ & 0.321 & 0.404 & 0.321 & 0.404 \\
\hline
\end{tabular}




\section{Table A9: Which Analysts Drop Coverage}

This table examines analysts' decisions to stop covering a firm. The dependent variable in all columns is the $D R O P$ dummy that equals one if the analyst stops producing earnings forecasts for the firm in the following year, and zero otherwise. Columns 1-2 conduct a panel OLS regression and columns 3-4 conduct a pooled logit regression. The main independent variables is the $I N$ dummy that takes the value of one if the analyst asks a question in the conference call and zero otherwise. Analyst level controls include: the average 12-month recommendation level of the analyst $(R E C D)$ on the firm, his recommendation relative to the consensus recommendation $\left(R E C D^{a d j}\right)$, the number of years the analyst has covered the firm $(L E N G T H)$, the number of years the analyst has been in the IBES database (CAREER), the number of stocks covered by the analyst, the number of stocks covered by the broker (a measure of broker size), whether the analyst is an all-star analyst, and whether the analyst is affiliated with a broker that underwrites for the firm in question. Firm level controls include: market capitalization, book to market ratio, past one year stock returns, monthly share turnover in the past year, daily idiosyncratic volatility in the previous year, number of analysts covering the firm, institutional ownership, and discretionary accruals. Columns 1 and 2 include firm*quarter fixed effects. Standard errors, clustered at both the firm and quarter level, are shown in parenthesis. *, **, *** denote significance at the $10 \%, 5 \%$, and $1 \%$ level, respectively.

\begin{tabular}{|c|c|c|c|c|}
\hline & $D R O P_{i, j, t+1}$ & $D R O P_{i, j, t+1}$ & $D R O P_{i, j, t+1}$ & $D R O P_{i, j, t+1}$ \\
\hline & [1] & [2] & [3] & [4] \\
\hline \multirow[t]{2}{*}{$I N_{i, j, t}$} & $-0.324 * * *$ & $-0.297 * * *$ & $-2.621 * * *$ & $-2.697 * * *$ \\
\hline & $(0.014)$ & $(0.014)$ & $(0.082)$ & $(0.065)$ \\
\hline \multirow[t]{2}{*}{$R E C D_{i, j, t}$} & -0.002 & $-0.006^{* * *}$ & & \\
\hline & $(0.002)$ & $(0.002)$ & & \\
\hline \multirow[t]{2}{*}{$R E C D_{i, j, t}^{a d j}$} & & & -0.010 & $-0.023^{*}$ \\
\hline & & & $(0.011)$ & $(0.013)$ \\
\hline \multirow[t]{2}{*}{$\operatorname{LENGTH}_{j, t}$} & & $-0.010^{* *}$ & & $-0.342^{* * *}$ \\
\hline & & $(0.004)$ & & $(0.034)$ \\
\hline \multirow[t]{2}{*}{ CAREER $_{j, t}$} & & $-0.009 *$ & & $-0.127 * * *$ \\
\hline & & $(0.005)$ & & $(0.033)$ \\
\hline \multirow[t]{2}{*}{$\# S T O C K_{j, t}^{\text {analyst }}$} & & $-0.144 * * *$ & & $-0.833 * * *$ \\
\hline & & $(0.005)$ & & $(0.034)$ \\
\hline \multirow[t]{2}{*}{$\#$ \#TOCK $K_{j, t}^{\text {broker }}$} & & $-0.010^{* * *}$ & & -0.039 \\
\hline & & $(0.004)$ & & $(0.029)$ \\
\hline \multirow[t]{2}{*}{$\operatorname{ALLSTAR}_{j, t}$} & & $-0.016^{* * *}$ & & $-0.146^{* * *}$ \\
\hline & & $(0.006)$ & & $(0.055)$ \\
\hline \multirow[t]{2}{*}{$A F F I L I A T E_{j, t}$} & & $0.024 * * *$ & & $0.147 * * *$ \\
\hline & & $(0.006)$ & & $(0.053)$ \\
\hline Other Controls & No & Yes & No & Yes \\
\hline No Obs. & 832,262 & 832,262 & 832,262 & 832,262 \\
\hline Adj/Pseudo R ${ }^{2}$ & 0.216 & 0.293 & 0.147 & 0.246 \\
\hline
\end{tabular}


Figure A1: Placebo Casting Episodes (Figure 2)

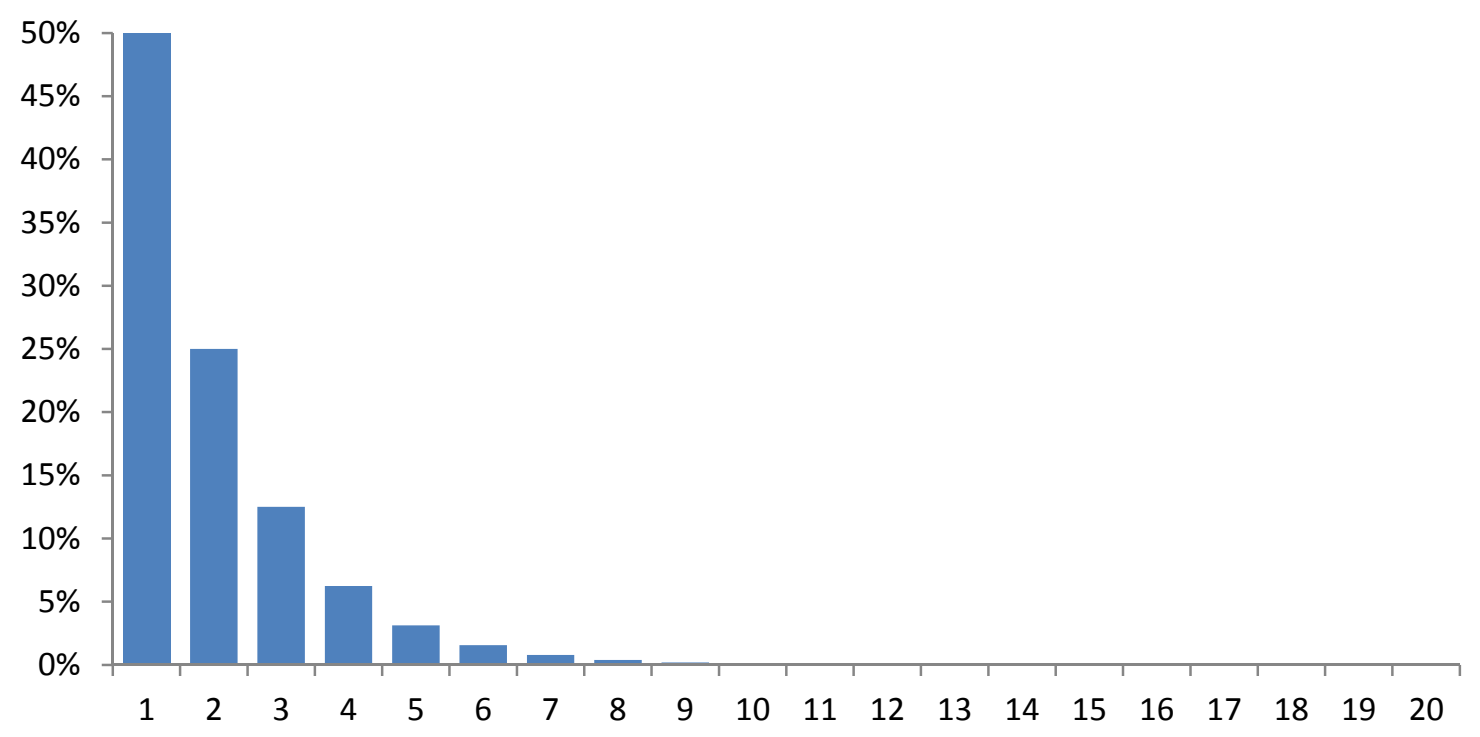

Placebo 1: a histogram of the number of consecutive quarters of casting spells (i.e., $R E C D(I N)>\operatorname{RECD}(O U T)$ ) under the assumption that firms calls on analysts randomly.

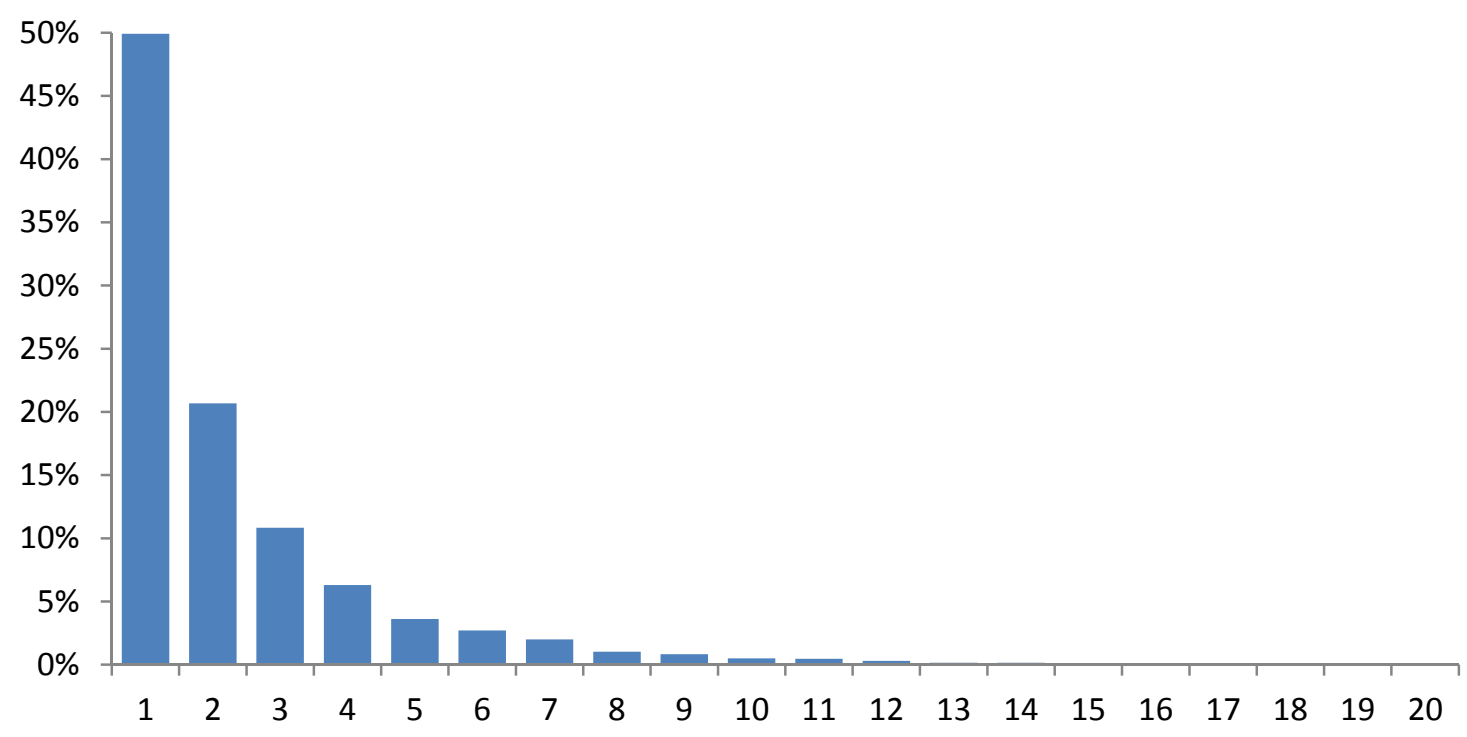

Placebo 2: a histogram of the number of consecutive quarters of non-casting episodes (that is, $R E C D(I N) \leq$ $\operatorname{RECD}($ OUT $))$. 


\section{Figure A2: Event-time Cumulative Abnormal Returns}

This figure plots event-time stock returns for the 12 months following an earnings conference call. Specifically, the figure examines the long-run return predictability of recommendation differentials between analysts that ask questions and those that do not in earnings conference calls: Specifically, we go long in stocks whose $R E C D(I N)$ is smaller than $R E C D(O U T)$ in the previous earnings call, and go short in stocks whose $R E C D(I N)$ is greater than $R E C D(O U T)$ in the previous earnings call. The figure presents DGTW characteristic-adjusted returns to this long-short portfolio, starting directly after the call, until 12 months later. Note that the next earnings announcement/conference call usually occurs in month three following the current call.

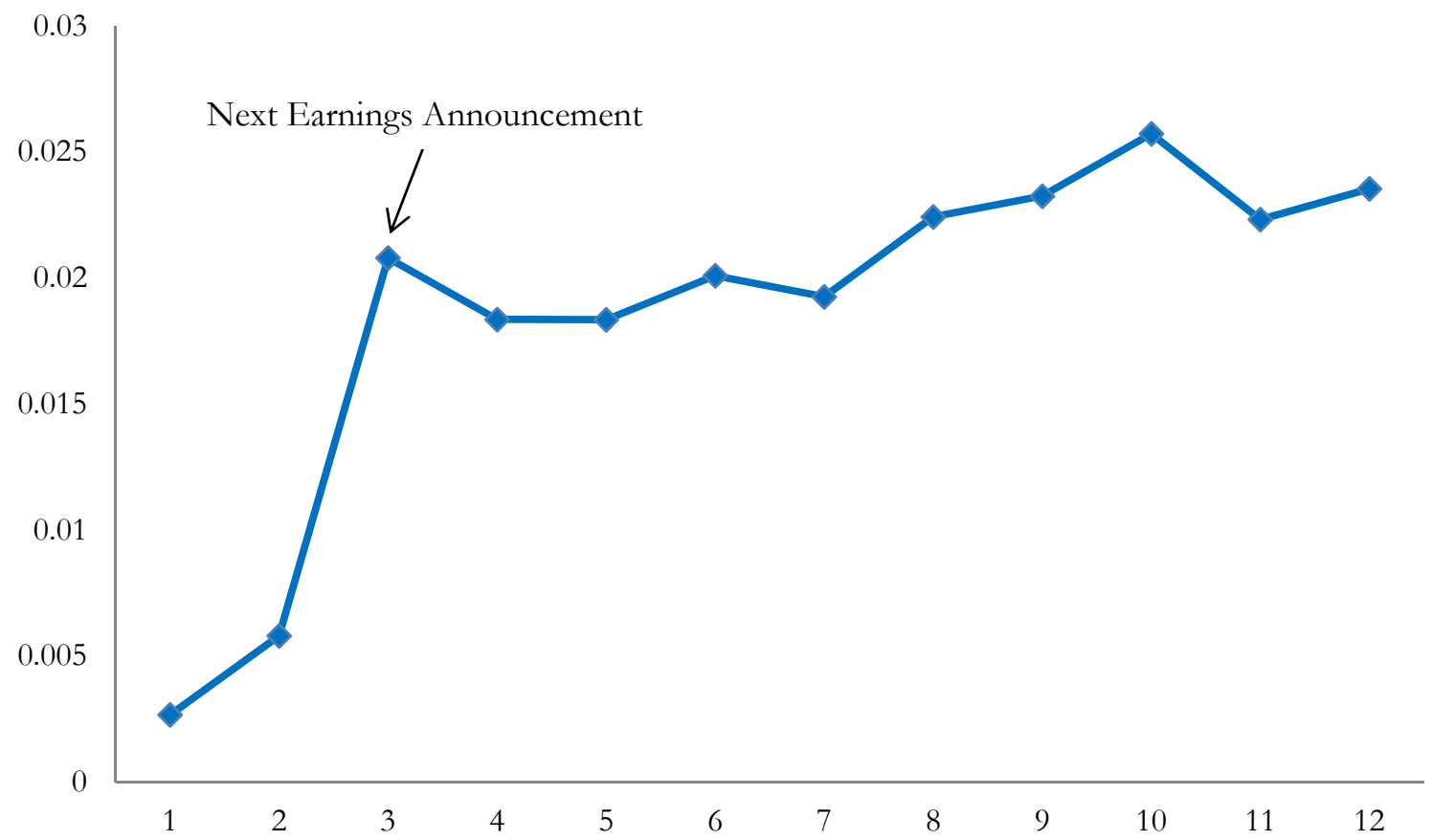

